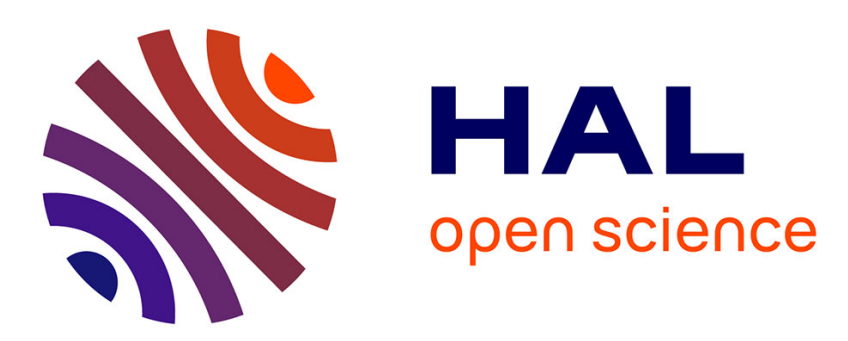

\title{
Topography and wettability characterization of surfaces manufactured by SLM and treated by chemical etching
}

Thomas Thenard, Anita Catapano, Rachele Allena, Michel Mesnard, Nicolas Saintier, El May Mohamed

\section{- To cite this version:}

Thomas Thenard, Anita Catapano, Rachele Allena, Michel Mesnard, Nicolas Saintier, et al.. Topography and wettability characterization of surfaces manufactured by SLM and treated by chemical etching. Mechanics of Advanced Materials and Structures, 2020, pp.1-18. 10.1080/15376494.2020.1836292 . hal-03156629

\section{HAL Id: hal-03156629 \\ https://hal.science/hal-03156629}

Submitted on 2 Mar 2021

HAL is a multi-disciplinary open access archive for the deposit and dissemination of scientific research documents, whether they are published or not. The documents may come from teaching and research institutions in France or abroad, or from public or private research centers.
L'archive ouverte pluridisciplinaire HAL, est destinée au dépôt et à la diffusion de documents scientifiques de niveau recherche, publiés ou non, émanant des établissements d'enseignement et de recherche français ou étrangers, des laboratoires publics ou privés. 


\title{
Topography and wettability characterization of surfaces manufactured by SLM and treated by chemical etching
}

\author{
T. Thenard ${ }^{\mathrm{a}, \mathrm{b}}$, A. Catapano ${ }^{c}$ (D) R. Allena ${ }^{\mathrm{b}}$, M. El May ${ }^{\mathrm{a}}$, N. Saintier ${ }^{\mathrm{a}}$, and M. Mesnard ${ }^{\mathrm{a}}$ \\ ${ }^{a}$ Arts et Métiers Institute of Technology, Université de Bordeaux, CNRS, INRA, Bordeaux INP, HESAM Université, Talence, France; ${ }^{\mathrm{b}}$ Arts et \\ Métiers Institute of Technology, Université Paris 13, Sorbonne Paris Cité, IBHGC, HESAM Université, Paris, France; 'Bordeaux INP, Université \\ de Bordeaux, Arts et Métiers Institute of Technology, CNRS, INRA, HESAM Université, Talence, France
}

\begin{abstract}
Selective Laser Melting process represents an interesting opportunity in the biomedical field to fabricate customized implants. However, the surface roughness of components obtained through additive manufacturing is a major limitation and affects the surface wettability. In the present work, chemical etching is adopted to deal with such an issue. To do so, the effects of chemical etching parameters (such as immersion time and composition of the solution) on the surface roughness, weight loss and wettability is analyzed. Different samples (obtained through different printing orientations) are considered. The tests show that the roughness and the wetting of the surfaces are improved thanks to chemical etching. As a major result, the most influencing parameters on surface wetting are two: the roughness and the material properties (which vary with samples depth).
\end{abstract}

\author{
KEYWORDS \\ Additive manufacturing; \\ topography; wettability; \\ selective laser melting; \\ biomedical implants; \\ chemical etching
}

\section{Introduction}

The additive manufacturing (AM) process is an innovative technology that makes it possible to manufacture complex $3 \mathrm{D}$ geometries with minimization of material waste [1]. One of the main advantages of the process is great freedom in terms of the geometry of the components and the possibility to use different materials for different regions during the process [2]. Besides, AM seems promising for challenging issues where weight minimization is a priority factor. Among the existing AM processes, those based on the fusion of a powder bed are the most developed ones. An example is the Selective Laser Melting (SLM) process [3]. SLM process consists in the addition of melting layers of a metallic powder bed, using a laser as power source. The interaction between the metallic powder and the laser creates the "selective melting" of specific parts of the layer according to the configuration of the slice. The same operation is repeated on all the slices composing the object, allowing the layer-by-layer manufacturing process. Such a process can be used for various applications, such as rapid prototyping, the manufacturing of spare parts, the creation of molds [4], etc. In particular, this process could let obtain very promising applications in the biomedical technologies. Indeed, it can be used to manufacture customized implants which can be adapted to the specific morphology of the patient through the use of radiological data. Moreover, the designer can act on the mesoscopic structure of the implant to optimize some required properties (e.g. stiffness, strength, weight, etc.).

Among the several aspects to be analyzed to completely characterize the properties and the physical behavior of components issued from SLM process, the surface roughness is of paramount importance especially for specific applications (e.g. aeronautical, biomedical, etc.). The experimental data on surface roughness of components issued from more classic industrial processes show a high variability, going from less than $1 \mu \mathrm{m}$ for machining $[5,6]$ to more than $100 \mu \mathrm{m}$ for casting [7]. In the case of the SLM, the surface exhibits a distinctive roughness, with a mean value around $15 \mu m$ [8-11]. This resulting roughness has various origins: (i) the staircase effect due to the orientation $\alpha$ of the surface during the manufacturing [12-14]; (ii) the texture created by melting bed during the process [15]; (iii) the sintered powder particles which are trapped in the neighboring of the melting bed area. Lhuissier et al. [16] defined (iii) as type I surface defect, and (i) and (ii) as type II surface defects. Type I surface defects can generate several issues, such as mechanical defects, or tolerance errors [17].

Indeed, the surface roughness obtained from the process could affect the surface interactions with its environment. In the literature and depending on the field of applications, it has been shown that the surface roughness could boost or reduce the performance of the surface $[18,19]$. For instance, it has been proven that the adhesive bond with a liquid state phase is higher on rough surfaces [20]. However, beyond an optimal value of the roughness, the strength of adhesive 


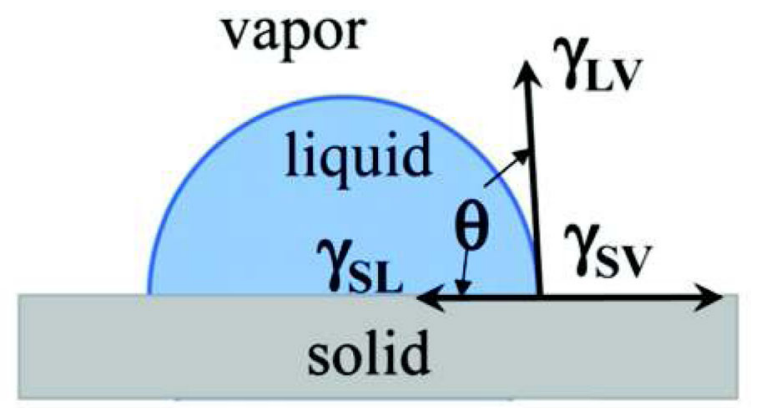

Figure 1. Schematic of the equilibrium of the phases from the study of Law et al. [21].

bonds starts decreasing. Speaking of the adhesive bond, the thermodynamic adhesion has to be considered when talking about interactions. From a thermodynamic point of view, adhesion can be defined as a thermodynamic work necessary to keep the equilibrium state of liquid, solid, and vapor phases (see Figure 1). This definition takes the form of the Dupre equation [21]:

$$
W_{a}=\gamma_{L V}+\gamma_{S V}-\gamma_{S L} .
$$

with $W_{a}$ the work of adhesion, $\gamma_{L V}$ the liquid/gas interfacial energy, $\gamma_{S V}$ the solid/gas interfacial energy, and $\gamma_{S L}$ the solid/liquid interfacial energy.

Very often, interfacial bonding is evaluated through the wettability of the surface [22]. Thus, wetting data may be used to estimate the thermodynamic adhesion of the surface $[23,24]$. Wettability is commonly characterized through the sessile drop method, that consists in the static measurement of a contact angle $\theta$ (see Figure 1) that arises from the equilibrium between solid, liquid, and gas phases [25]. When using water as a liquid phase, a surface is defined as hydrophilic for $\theta<90^{\circ}$ and hydrophobic for $\theta \geq 90^{\circ}$ [21, 26]. It must be pointed out that this definition is not absolute. Using this method, we are able to calculate the surface free energy $\gamma_{S L}$, using the Young-Dupre relation [27]:

$$
\gamma_{S V}=\gamma_{S L}+\gamma_{L V} \cos \theta \text {. }
$$

Typical values of wettability measured on SLM surfaces containing powder particles seem to show a hydrophobicity of the surface with contact angle $\theta \sim 100^{\circ}$ for Ti-6Al-4V (TA6V) [28], reflecting a low surface energy, thus a low thermodynamic adhesion. However, several fields of applications promote the hydrophilic surfaces, with contact angles inferior to $90^{\circ}$. More precisely, in the case of machined TA6V flat surface, $\theta \in\left[70^{\circ}, 90^{\circ}\right]$ [29]. Therefore, in the case of SLM components, the hydrophobic surface properties can be assigned to the presence of sintered particles trapped into the surface.

In order to solve this issue, surface treatment can be considered. Among the existing surface treatments, the chemical etching seems to be the most adapted to the SLM process. Indeed, chemical etching is compatible with the $3 \mathrm{D}$ complexity of typical parts issued from the SLM process, and it is relatively easy to execute [16]. This typical chemical etching process consumes the Ti element on the surface. Then, the treatment enables to smooth the surface, allowing to decrease the surface roughness and increasing the surface wettability. Indeed, Zahran et al. [30] shows that for an etching solution of $10 \% \mathrm{HF}$ on commercially pure polished $\mathrm{Ti}$, a decrease of contact angle from $\theta \sim 60^{\circ}$ to $\theta \sim 40^{\circ}$ is observed. Therefore, contrary to several studies on flat surfaces treated using chemical etching to increase roughness, and so, to improve wetting [31], on SLM-based surfaces, the primary goal of the acid etching is to remove the sintered particles from the surface to decrease the roughness, and so to try to maximize wettability. Thus, the knowledge of the chemical etching kinetic on the topology and the wetting on SLM-based surfaces is of fundamental importance.

In this paper, the aim is to improve the roughness and the wettability of TA6V surfaces obtained by SLM. Although TA6V alloy, issued from classical manufacturing processes, has been investigated many times, the originality of our approach consists in analyzing the chemical etching process in order to improve the surface conditions of SLM-based surfaces in terms of roughness and wettability. In particular, the variation of roughness due to the printing orientation $\alpha$, with respect to the printing plate, will be considered. The study will focus on the application to the biomedical field. More precisely, medical devices (such as implants or prostheses) must present a higher sensitivity to wetting, with a high hydrophilicity of surfaces in order to boost the cellular adhesion and proliferation on the surface [32, 33]. For instance, Vogler et al. [34] have shown that a better initial cell adhesion and a larger contact area of the cell is registered on wettable surfaces compared to hydrophobic materials. On the other hand, Li et al. [35] have shown an increase of cell detachment on the hydrophobic surface. Besides, the roughness is also a strictly related parameter to consider. Indeed, Wennerberg et al. [36] show that a moderate roughness, between 1 and $2 \mu m$, gives an enhanced bone response and promotes better cell adhesion, motility, and shape, which are essential for efficient early osseointegration. Soro et al. [37] evaluated the impact of etching on TA6V lattices specimens for biological applications and have shown the complex nature of the local roughness variation as a function of the edging time and local surface orientation with respect to the building direction, fully supporting the need for the detail analyses proposed in the present work. Thus, to attain the main goal of the present work, the chemical etching parameters to obtain high surface energy with moderate hydrophilicity $\left(\theta<90^{\circ}\right)$ and low roughness value (average roughness belonging to $[1 \mu m-2 \mu m])$ is determined. To this purpose, the first part of the study focuses on the characterization of the SLM surface and its different properties. Then, the parameters of the chemical etching and their influence on the surface roughness and wettability are analyzed. To finish, an analysis of the chemical etching depending on $\alpha$ is made to evaluate its effectiveness. Some general remarks and conclusions end the paper.

\section{Materials and methods}

\subsection{Sample preparation and chemical etching protocol}

Disks of titanium alloy TA6V were fabricated with a thickness of $3 \mathrm{~mm}$ and a diameter of $11.5 \mathrm{~mm}$. Those disks were produced from TA6V powder, using the AM machine 


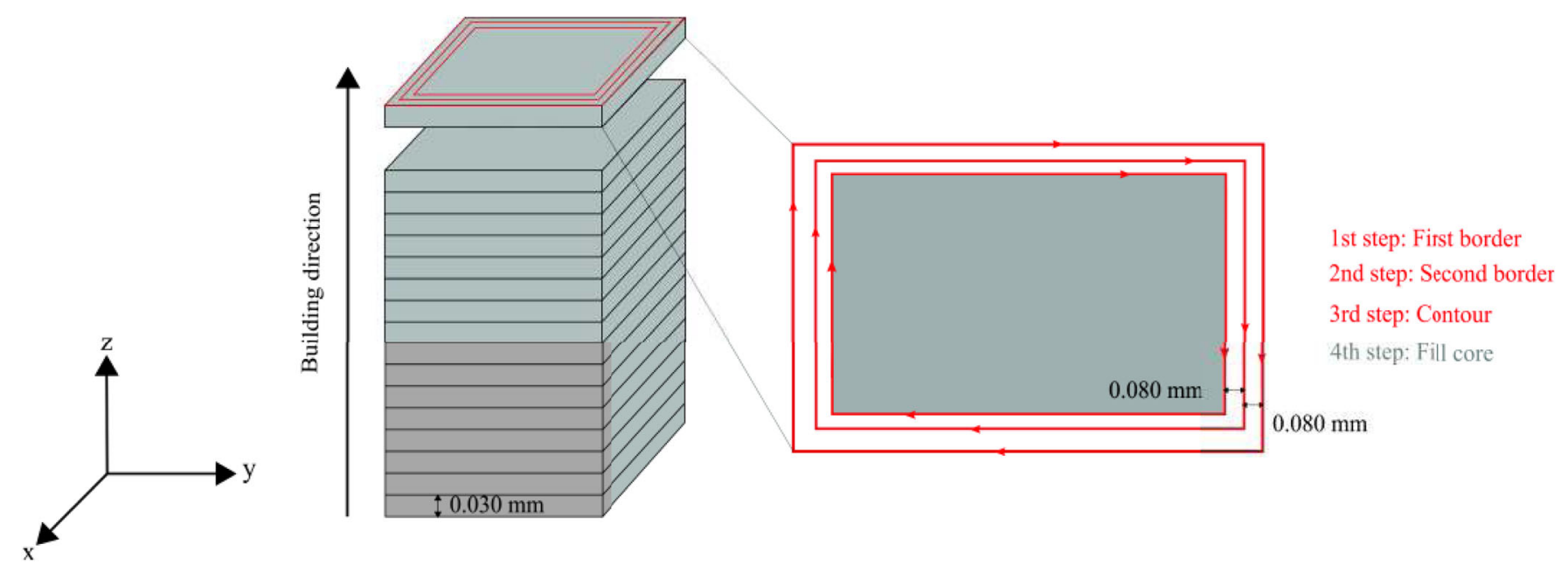

Figure 2. Scan strategy of the SLM process. Each layer is represented by a rectangular parallelepiped.

Table 1. Values of SLM nominal parameters for the borders and contour, and the core.

\begin{tabular}{lccc}
\hline Borders and Contour parameters & \multicolumn{3}{c}{ Core parameters } \\
\hline Power P $(\mathrm{W})$ & 150 & Power P $(\mathrm{W})$ & 275 \\
Scan speed V $(\mathrm{mm} / \mathrm{s})$ & 450 & Scan speed V $(\mathrm{mm} / \mathrm{s})$ & 1100 \\
Hatch distance $\mathrm{h}(\mathrm{mm})$ & 0.08 & Hatch distance $\mathrm{h}(\mathrm{mm})$ & 0.12 \\
Layer thickness e $(\mathrm{mm})$ & 0.03 & Layer thickness e $(\mathrm{mm})$ & 0.03 \\
Energy density E $\left(\mathrm{J} / \mathrm{mm}^{3}\right)$ & 138.9 & Energy density E $\left(\mathrm{J} / \mathrm{mm}^{3}\right)$ & 69.4 \\
\hline
\end{tabular}

$\mathrm{SLM}^{280}$ (2.0 of SLM SOLUTIONS GROUP AG). Each layer of the AM process was $30 \mu \mathrm{m}$ thick and was generated using a two-step laser path: first, the external perimeter of the layer (defined by two borders and one contour in red in Figure 2) was fused; then, the internal core was filled (defined by the gray region in Figure 2).

The borders and contours were generated using an energy density of $139 \mathrm{~J} / \mathrm{mm}^{3}$ whereas the internal core was generated using an energy density of $69 \mathrm{~J} / \mathrm{mm}^{3}$. Each energy density was defined by a nominal value of laser power $\mathrm{P}$, scan speed $\mathrm{V}$, hatching space $\mathrm{h}$, and layer thickness e, whose values are defined in Table 1. After fabrication, the support structures were removed and the samples were cleaned using ethanol, then distilled water within an ultrasonic tank in order to remove the unsintered powder.

To analyze the chemical etching process, three protocols were defined in this study:

\section{Protocol $n^{\circ} 1$.}

A set of disks oriented at $\alpha=90^{\circ}$ (plane (x,y) being the printing plane, see Figure 3 ) were fabricated, then chemically etched in a mixtures of hydrofluoric and nitric acids. Three different acid baths were tested on this set of samples. For each bath, 5 different times of immersion were tested: $5 \mathrm{~min}, 10 \mathrm{~min}, 15 \mathrm{~min}, 20 \mathrm{~min}$, and $30 \mathrm{~min}$. Acid composition of the batches are summarized in Table 2 .

\section{Protocol $n^{\circ} 2$.}

A set of disks still oriented at $\alpha=90^{\circ}$ were produced, then polished with a set of abrasive papers (chronological sequence: $\mathrm{P} 80 \rightarrow \mathrm{P} 100 \rightarrow \mathrm{P} 400 \rightarrow \mathrm{P} 800 \rightarrow \mathrm{P} 1200 \rightarrow$ P2400). A chemical etching in a solution composed of $3 \%$
HF and $10 \% \mathrm{HNO}_{3}$ was then applied with 5 different times of immersion: $5 \mathrm{~min}, 10 \mathrm{~min}, 15 \mathrm{~min}, 20 \mathrm{~min}$, and $30 \mathrm{~min}$.

\section{Protocol $n^{\mathbf{o}} 3$.}

Four sets of specimens were produced by SLM, each set being defined by a different inclination $\alpha$ of the plane of the disk with respect to the $(\mathrm{x}, \mathrm{y})$ printing plane (Figure 3$): 0^{\circ}$, $30^{\circ}, 60^{\circ}$, and $90^{\circ}$. For each set, a chemical etching in a solution composed of $3 \% \mathrm{HF}$ and $10 \% \mathrm{HNO}_{3}$ was then applied for 30 minutes.

For each protocol, each chemical etching was realized within an ultrasonic tank in order to obtain a homogeneous etching on all the surface. After the chemical etching, the samples were cleaned using first ethanol, then distilled water within an ultrasonic tank in order to remove all traces of the etching solution. The mass of each sample was measured before and after chemical polishing.

\subsection{Surface topography analysis}

3D surface roughness data of each sample were acquired using an optical profilometer AltiSurf 500 (AltiMet, France) in chromatic confocal mode. The area of $1 \mathrm{~mm} \times 1 \mathrm{~mm}$ was measured with an in-plane resolution of $5 \mu \mathrm{m}$ and a vertical resolution of $10 \mathrm{~nm}$. The surface measurements were made following a regular grid mapping of the surface and a grid step size of $5 \mu \mathrm{m}$. The roughness was measured orthogonally to the inclination plane. The $3 \mathrm{D}$ surface roughness measurements were made on two representatives samples of each surface type (raw SLM, Protocols $n^{\circ} 1,2,3$ ) and repeated 3 times randomly on the surface. The optical profilometer provided data on the topographic parameters: arithmetic mean roughness $R a$, root mean square roughness $R_{q}$, the maximum height $R_{z}$, skewness $R_{s k}$, Kurtosis parameter $R_{k u}$. The definition of all the parameters can be found in the study of Gadelmawla et al. [38]. Besides, we also calculated the developed area ratio $S_{w}$, defined as the ratio between the area of the real surface and the area of the projected surface. In addition, the morphology of each material surface was examined under a white light microscope VHX-5000 (Keyence, Itasa, USA). The morphology was evaluated using 


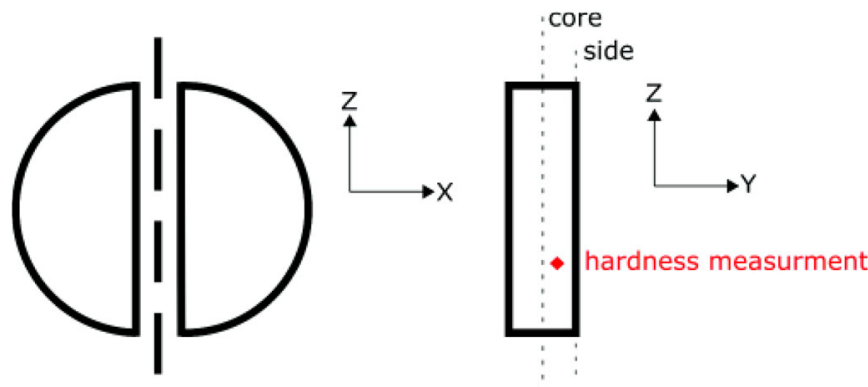

Figure 3. Sample cut in the Y-Z plane for hardness measurement.

Table 2. Composition of the hydrofluoric and nitric acids baths for the chemical etching.

\begin{tabular}{lcc}
\hline$n^{\circ}$ & $\mathrm{HF}(\%)$ & $\mathrm{HNO}_{3}(\%)$ \\
\hline 1 & 3 & 10 \\
2 & 3 & 20 \\
3 & 10 & 10 \\
\hline
\end{tabular}

$1600 \times 1200$ pixel images and $3 \mathrm{D}$ reconstruction of the surface using the software included with the system. Moreover, a reference group of untreated SLM surface with an inclination of $\alpha=90^{\circ}$ was examined under a scanning electron microscope (Zeiss EVO50 HD, Germany).

\subsection{Wettability and surface energy measurement}

In the case of a free ideal solid surface the contact angle correspond to the definition of Young's contact angle. However, when dealing with real surfaces presenting micro and nano-roughness the notion of apparent contact angle $\theta_{\text {app }}$ must be used. The apparent contact angle is defined as the angle between the apparent surface and the liquid-fluid interface tangent, see $[23,24,39,40]$. In the present work, apparent contact angle $\theta_{a p p}$ and surface energy measurements were made using the contact angle system DSA 30 (Kruss, Germany). Nine measurements on three samples of each surface type (raw SLM, Protocols $n^{\circ} 1,2,3$ ) were performed using 2 media (distilled water and diiodomethane). During the tests, $5 \mu \mathrm{L}$ of each media were placed on the surface, then analyzed using the software provided with the DSA 30 system. The surface energy was determined from the apparent contact angle $\theta_{a p p}$ by post-processing, using the Owen-Wendt method [25]. Each media was characterized by a polar component $\sigma_{L}^{p}$ and a dispersive component $\sigma_{L}^{d}$. From the contact angle measurement and by regression, we were able to determine the polar $\left(\sigma_{S}^{p}\right)$ and dispersive $\left(\sigma_{S}^{d}\right)$ component of the surface, using the following equation:

$$
\frac{\sigma_{L}\left(1+\cos \theta_{a p p}\right)}{2 \sqrt{\sigma_{L}^{d}}}=\sqrt{\sigma_{S}^{p}} \sqrt{\frac{\sigma_{L}^{p}}{\sigma_{L}^{d}}}+\sqrt{\sigma_{S}^{d}} .
$$

Then, the free energy surface (equal to $\sigma_{S}^{p}+\sigma_{S}^{d}$ ) was calculated. In the results section (Sec. 3), all $\theta_{a p p}$ are measured using water.

\subsection{Hardness measurement}

The surface stiffness was evaluated using micro-indentation hardness tests. One representative sample from the reference group of untreated SLM surface with inclination $\alpha=90^{\circ}$ was chosen, and cut in the local Y-Z plane to obtain the section of the sample (see Figure 3). Hardness measurements from the external border to the internal core were taken. Hardness measurements were performed with a $500 \mathrm{~g}$ load using a Vicker hardness tester. A series of 10 tests were conducted along evenly-spaced $150 \mu \mathrm{m}$ interval from the external border to the internal core and the process was repeated three times. In order to analyze the relation between hardness and wetting, a set of disks were produced by with an inclination of $\alpha=90^{\circ}$, then machined along the y direction to remove an external layer of thickness $t$. Six values of $t$ were set: $0.2 \mathrm{~mm}, 0.3 \mathrm{~mm}, 0.4 \mathrm{~mm}, 0.5 \mathrm{~mm}, 0.7 \mathrm{~mm}$, and $0.9 \mathrm{~mm} .5$ samples were analyzed for each value of $t$.

\subsection{Statistical analysis}

Data were analyzed with a Kruskal Wallis test, followed by a post-hoc Spearman test. The Kruskal Wallis test analyses the null hypothesis and is defined by a p-value $p$ which will be considered as significant if $p<0.05$. The Spearman test analyses the correlation between two sets of data and is defined by a correlation value $c$ and a p-value $p$ (also in this case, $p$ will be considered as significant if $p<0.05$ ).

\section{Results}

\subsection{Characterization of SLM surfaces}

Figure 4 depicts the morphologies of surfaces obtained for 4 different orientations $\alpha$ of the specimen with respect to the printing plane (i.e. $\alpha=0^{\circ}, 30^{\circ}, 60^{\circ}$, and $90^{\circ}$ ). Table 3 presents the values of $R a, R q, R z, R s k, R k u$ and $S_{w}$ parameters relative to the surfaces at the 4 different orientations. At $\alpha=0^{\circ}$, the surface presents a wavy morphology created by the cooling of the melting bed. An increase of roughness is observed when $\alpha$ passes from $0^{\circ}$ to $30^{\circ}$, with an increase of average roughness $R a$ from $9.35 \mu \mathrm{m}( \pm 1.44)$ to $15.33 \mu \mathrm{m}( \pm$ 1.07) (see Table 3). $R q, R z$, and $S_{w}$ follow the same evolution. The negative value of Rsk at $\alpha=30^{\circ}$ points out the predominance of peaks on the surface. We can assume that the increase of roughness from $\alpha=0^{\circ}$ to $30^{\circ}$ results from the combining effect of type II defects, via the staircase effect (the AM of a tilted surface takes place by the superposition of shifted layers) which is more pronounced with $\alpha$, and type I defects (sintered particles) on the surface (see Figure $4 \mathrm{~b})$. The Kurtosis value $(R k u)$ is larger than 3 for the two orientations. This confirms a predominance of sharp peak distribution on $\alpha=0^{\circ}$ and $30^{\circ}$ surfaces, accentuated by the type I defects at $\alpha=30^{\circ}$.

When $\alpha$ changes from $30^{\circ}$ to $60^{\circ}$, the morphology evidences an increase of density of type I defects (sintered particles) with an increase of $S_{w}$ from $2.32( \pm 0.09)$ to $2.81( \pm$ 0.07) (see Table 3). A decrease of $R a$ is simultaneously observed whereas no significant differences are found for $R q$ 


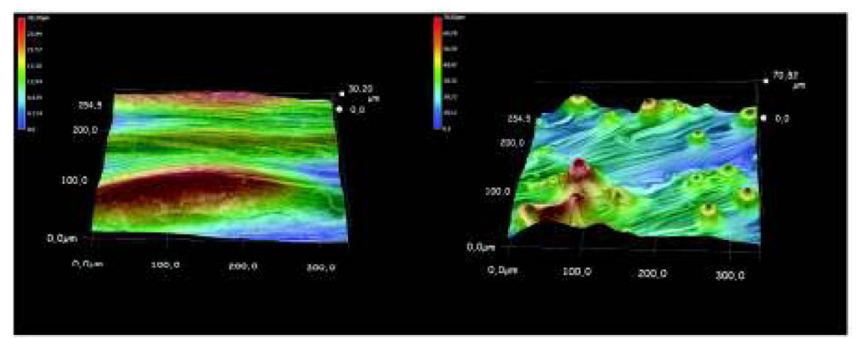

(a) $0^{\circ}$

(b) $30^{\circ}$

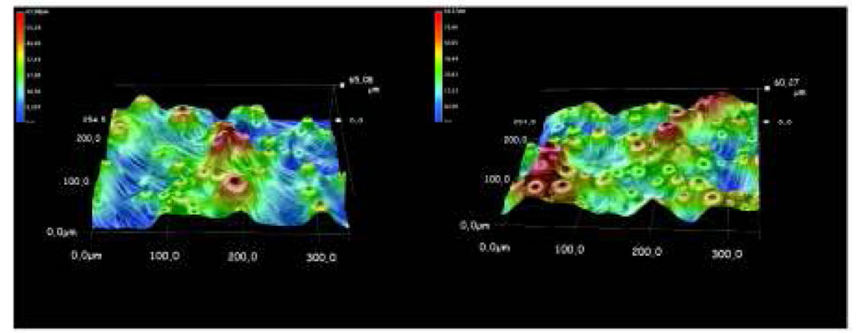

(c) $60^{\circ}$

(d) $90^{\circ}$

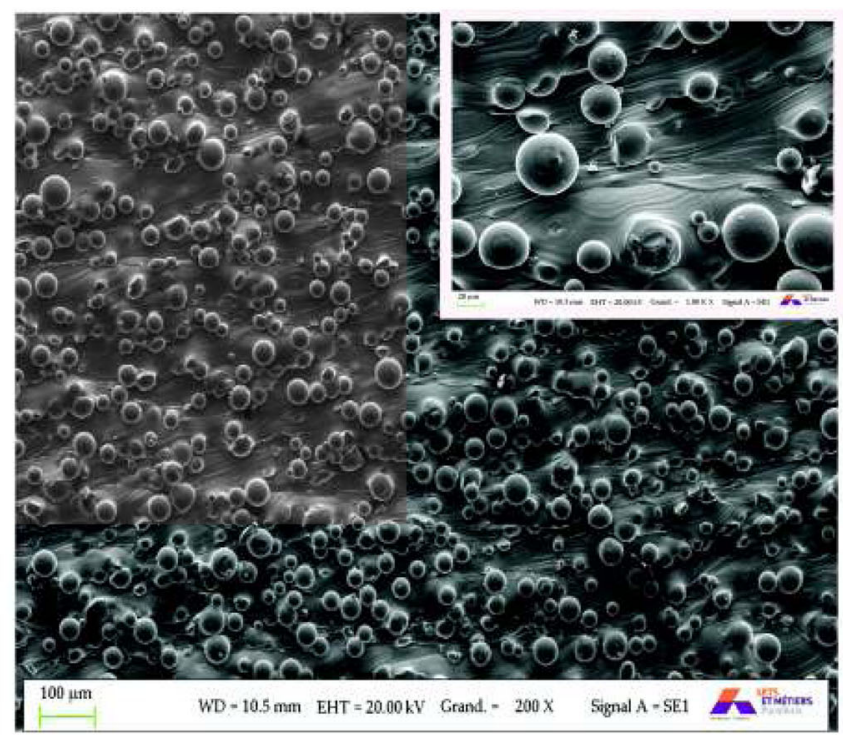

(e) SEM image of SLM surface with a $90^{\circ}$ orientation

Figure 4. 3D morphologies of the surface orientations. (a:d) gives the surface topographies for $\alpha=0^{\circ}, 30^{\circ}, 60^{\circ}$, and $90^{\circ}$. (e) gives a SEM image of the surface at $\alpha=90^{\circ}$.

Table 3. Values of roughness parameters depending on $\alpha$.

\begin{tabular}{lccccc}
\hline & $R a(\mu m)$ & $R q(\mu m)$ & $R z(\mu m)$ & $R s k(\mu m)$ & $R k u(\mu m)$ \\
\hline $0^{\circ}$ & $9.35( \pm 1.44)$ & $11.89( \pm 1.56)$ & $64.29( \pm 12.15)$ & $-0.21( \pm 0.18)$ & $4.02( \pm 1.08)$ \\
$30^{\circ}$ & $15.33( \pm 1.07)$ & $20.25( \pm 1.11)$ & $133.13( \pm 4.42)$ & $0.88( \pm 0.21)$ & $4.8( \pm 0.56)$ \\
$60^{\circ}$ & $13.77( \pm 0.79)$ & $18.19( \pm 1.17)$ & $134.93( \pm 11.72)$ & $0.96( \pm 0.24)$ & $5.22( \pm 1.26)$ \\
$90^{\circ}$ & $15.75( \pm 1.15)$ & $19.9( \pm 1.2)$ & $130.8( \pm 9.6)$ & $0.56( \pm 0.4)$ & $3.71( \pm 0.11)$ \\
\hline
\end{tabular}

and $R z$. Therefore, we can assume that the increase of roughness with the density of type I defects is counterbalanced by the decrease of roughness due to the mitigation of the staircase effect for higher $\alpha$. Finally, when $\alpha$ changes from $60^{\circ}$ to $90^{\circ}$, the roughness of the sample surface keeps reducing. Therefore, this seems to follow the considerations still made for $\alpha=30^{\circ}$ and $60^{\circ}$. The roughness deriving from the type II defects (staircase effect) becomes negligible compared the roughness due to the type I defects when $\alpha$ increases. An increase of $R a$ and $S_{w}$ is measured, whereas $R z$ and $R q$ do not vary considerably. A decrease of $R k u$ value from $\alpha=60^{\circ}$ to $90^{\circ}$ is measured. Rsk is still positive, underlining the predominance of peaks created by the particles.

Concerning the wettability of raw SLM samples, surfaces obtained are mostly hydrophobic (whereby $\theta_{\text {app }}>90^{\circ}$ ) (Figure 5). Concerning samples fabricated at $\alpha=0^{\circ}$, the surface presents a $\theta_{a p p}$ of $75^{\circ}( \pm 4.1)$ for a surface energy of 60 $m J / m^{2}( \pm 4.1)$. Thus, this surface can be defined as moderately hydrophilic.

Increasing the fabrication angle $\alpha$ from $0^{\circ}$ to $30^{\circ}$ results in an increase of $\theta_{\text {app }}$ up to $99.3^{\circ}$ ( \pm 3.7 ), and a relative decrease of surface energy down to $40.5 \mathrm{~mJ} / \mathrm{m}^{2}( \pm 1.9)$. For specimens fabricated at an inclination greater than $30^{\circ}$, no significant differences are found in terms of $\theta_{a p p}$ and surface energy ( $p=0.85$, Kruskal-Wallis method). No correlations are found between $R a$ and the $\theta_{a p p}$ or the surface energy $(p=0.2$, Spearman method). However, the variation of $\theta_{\text {app }}$ when $\alpha$ passes from $\alpha=0^{\circ}$ to $30^{\circ}$ seems to match the emergence of type I defects. One assumption can be that the presence of type I defects could cause the hydrophobicity of the surface.

\subsection{Characterization of SLM TA6V material}

To characterize the evolution of material properties inside SLM-based components, an analysis of microhardness has been realized on $\alpha=90^{\circ}$ oriented samples according to hardness measurement tests described in Section 2.4. Figure 6 shows an increase of hardness with the depth, from 341 $H V( \pm 1.5)$ at $0.2 \mathrm{~mm}$ to $368 \mathrm{HV}( \pm 2)$ at $0.5 \mathrm{~mm}$ depth from the outer surface of the sample. From $0.5 \mathrm{~mm}$ to $0.9 \mathrm{~mm}$, no significant differences are found $(p=0.6$, Kruskal-Wallis method), proving a stabilization of the material properties. Those results highlight the presence of a gradient of material properties along the thickness of SLMbased components.

Figure 7 presents the results of $\theta_{a p p}$ and surface energies for different in depth values obtained through the same machining process (see Section 2.4). At an in depth of $0.2 \mathrm{~mm}$, we measure a $\theta_{\text {app }}$ of $86.4^{\circ}( \pm 4.2)$ and a surface energy of $49.3 \mathrm{~mJ} / \mathrm{m}^{2}$ ( \pm 3.45 ). No significant differences are found between $\theta_{a p p}$ at in depth of $0.2,0.3$, and $0.4 \mathrm{~mm}$ $(p=0.78$, Kruskal-Wallis method). A significant decrease of $\theta_{a p p}$ is measured when passing from an in depth of $0.4 \mathrm{~mm}$ to $0.5 \mathrm{~mm}$ ( $p=0.009$, Kruskal-Wallis method), whose $\theta_{a p p}$ varies from $85.8^{\circ}( \pm 7.2)$ to $69.6^{\circ}( \pm 7.8)$. This is reflected by an increase of surface energy from $50.2 \mathrm{~mJ} / \mathrm{m}^{2}$ ( \pm 5.1) to $66.4 \mathrm{~mJ} / \mathrm{m}^{2}( \pm 8.6)$. Then, a stabilization of the value of $\theta_{a p p}$ and surface energy is measured, with no significant differences between the different in depth surface of 0.5, 0.7, and $0.9 \mathrm{~mm} \quad(p=0.3$, Kruskal-Wallis method). This result matches the trend of the gradient of material. 


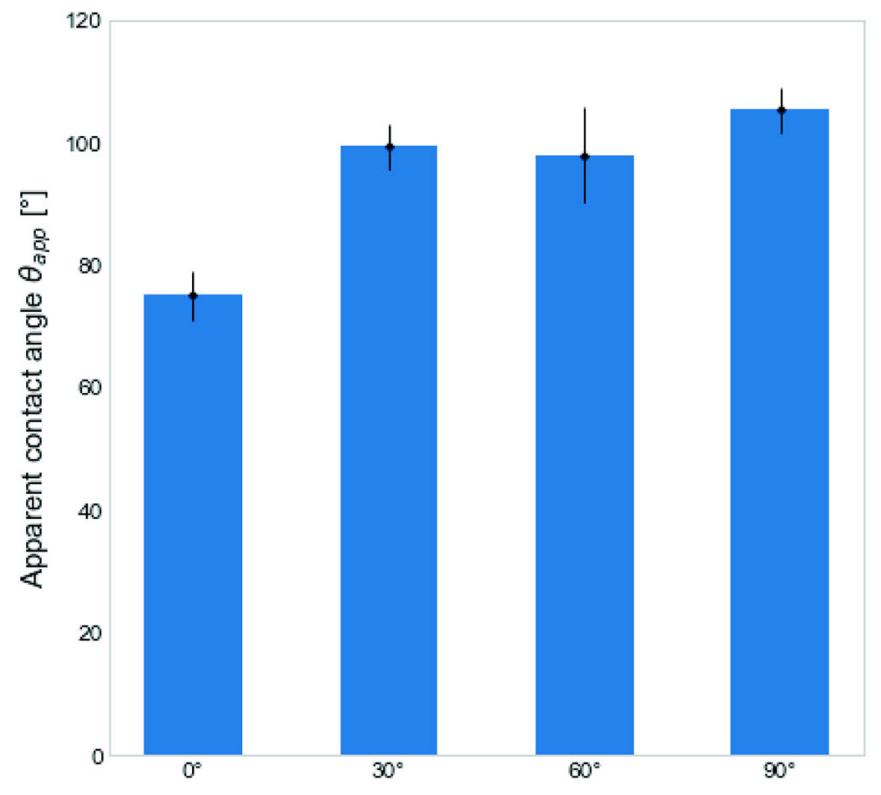

(a) Values of $\theta_{\text {app }}$

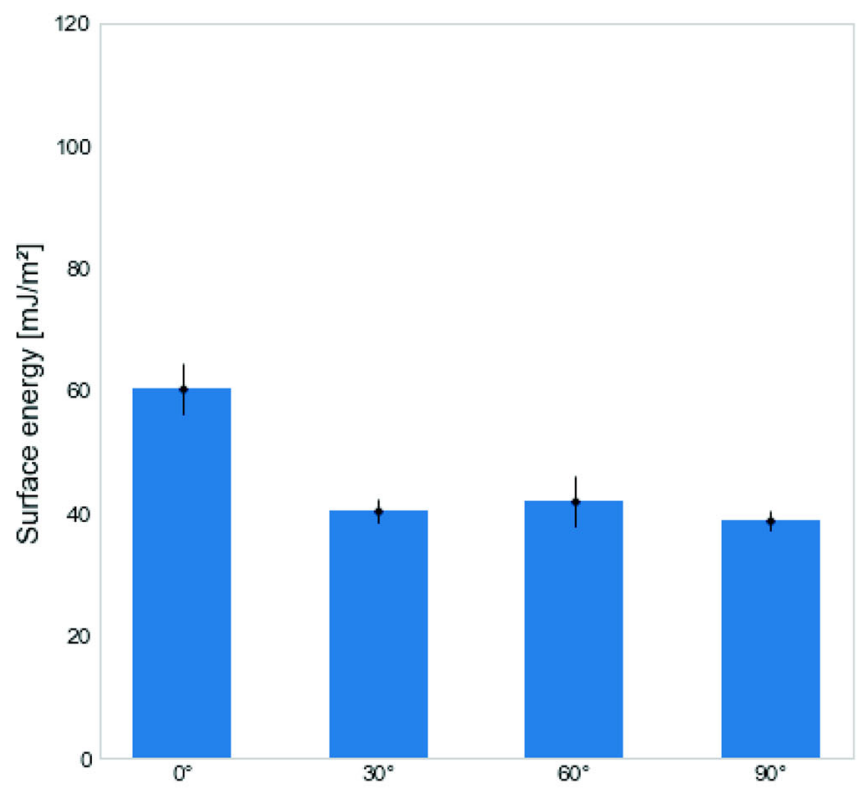

(b) Values of surface energies

Figure 5. Values of $\theta_{\text {app }}$ and surface energy depending on $\alpha$.
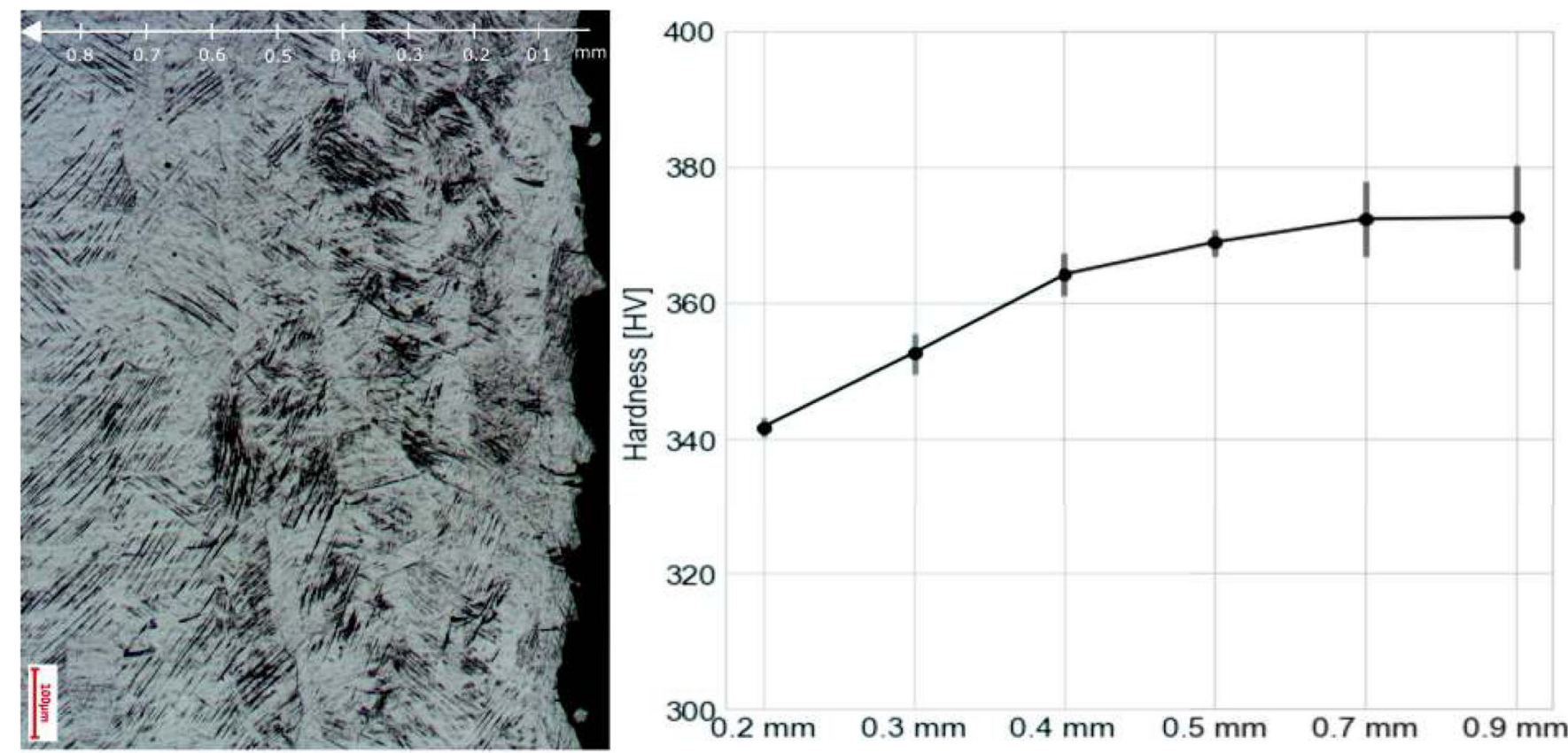

Figure 6. Value of hardness as function of the distance from the outer surface.

\subsection{Chemical etching analysis}

Figure 8 shows the morphology of SLM-based surfaces treated with chemical etching using protocol $n^{\circ} 1$. In terms of morphology, Figure 8 shows the elimination of type I defects at $t=5 \mathrm{~min}$, for all the chemical etching compositions. Besides, a decrease of surface amplitude with the increase of immersion time is also observed for those 3 compositions with however significant differences between them. $3 \% \mathrm{HF} / 10 \% \mathrm{HNO}_{3}$ and $3 \% \mathrm{HF} / 20 \% \mathrm{HNO}_{3}$ treatments keep the traces of the SLM process and a resulting anisotropy of the surface even after $30 \mathrm{~min}$ of immersion, whereas $10 \% \mathrm{HF} / 10 \% \mathrm{HNO}_{3}$ removes all process traces on the surface.
Table 4 gives the value of the roughness parameters for the different compositions and immersion times. For a bath composition of $3 \% \mathrm{HF} / 10 \% \mathrm{HNO}_{3}$, a decrease of $\mathrm{Ra}$ is measured, from $14.5 \mu \mathrm{m}( \pm 2.6)$ at $5 \mathrm{~min}$ to $6.8 \mu \mathrm{m}( \pm 0.7)$ at $30 \mathrm{~min} . R q$ and $R z$ follow the same evolution. Rsk takes positive values during the etching, with thus a predominance of peaks, except for $30 \mathrm{~min}$ where local porosities (i.e. local cavities) start to appear (reflected by $R s k<0$ ). A decrease of $R k u$ is also observed during the etching, from $5 \mathrm{~min}$ to $30 \mathrm{~min}$. However, those values stay higher than or equal to 3. This can be read as a decrease of the sharp peaks in the surface in favor of more rounded peaks. In terms of 


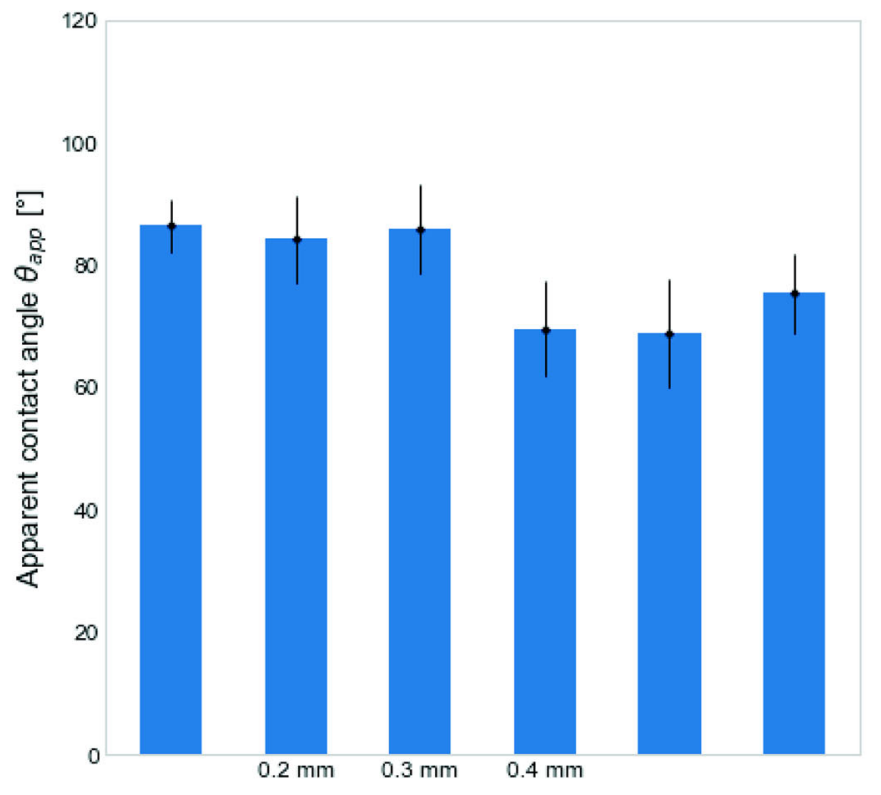

(a) Values of $\theta_{a p p}$.

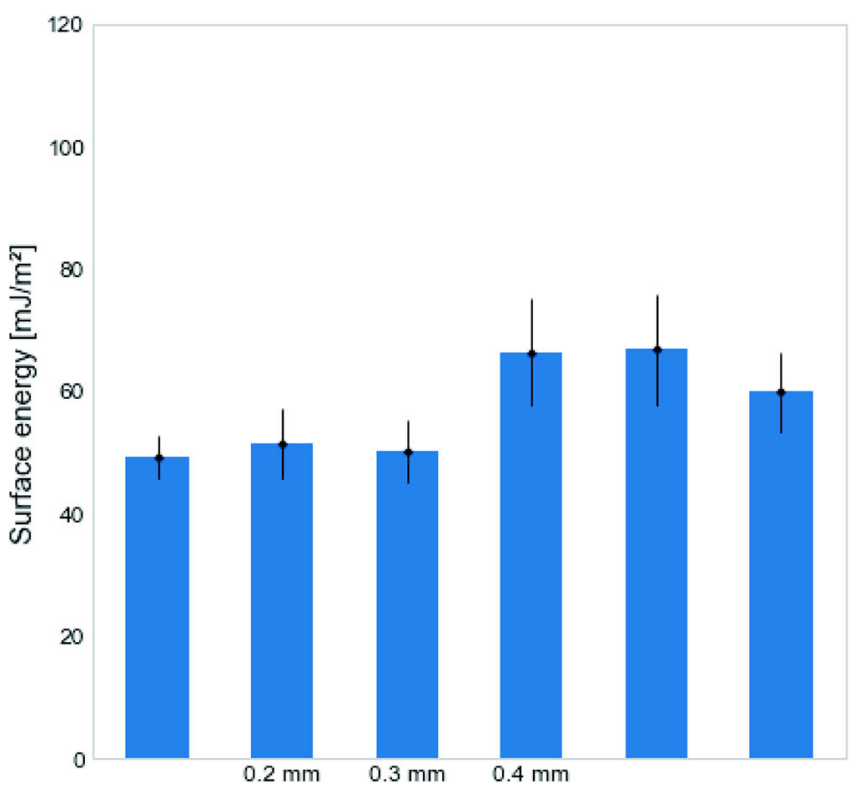

(b) Values of surface energies.

Figure 7. $\theta_{a p p}$ and surface energies as function of the distance to the surface.

Table 4. Values of roughness parameters for the different chemical etching compositions and durations.

\begin{tabular}{|c|c|c|c|c|c|c|c|}
\hline Chemical polishing composition & time (min) & $R a(\mu m)$ & $R q(\mu m)$ & $R z(\mu m)$ & Rsk & $R k u$ & $S_{w}$ \\
\hline \multirow[t]{5}{*}{$3 \% \mathrm{HF} / 10 \% \mathrm{HNO}_{3}$} & 5 & $14.5( \pm 2.55)$ & $16.7( \pm 2.2)$ & $101.3( \pm 13.6)$ & $0.47( \pm 0.13)$ & $3.75( \pm 0.09)$ & $2.02( \pm 0.07)$ \\
\hline & 10 & $12.8( \pm 1.94)$ & $16.3( \pm 2.7)$ & $95.5( \pm 18.7)$ & $0.64( \pm 0.07)$ & $3.63( \pm 0.4)$ & $1.71( \pm 0.2)$ \\
\hline & 15 & $9.7( \pm 1.9)$ & $12.2( \pm 1.7)$ & $74.1( \pm 8.6)$ & $0.27( \pm 0.17)$ & $3.26( \pm 0.4)$ & $1.41( \pm 0.08)$ \\
\hline & 20 & $8.4( \pm 2.23)$ & $10.7( \pm 2.8)$ & $50.8( \pm 6.2)$ & $0.32( \pm 0.18)$ & $3.15( \pm 0.31)$ & $1.34( \pm 0.07)$ \\
\hline & 30 & $6.8( \pm 0.66)$ & $8.4( \pm 0.6)$ & $40.7( \pm 4.6)$ & $-0.03( \pm 0.28)$ & $3( \pm 0.8)$ & $1.26( \pm 0.09)$ \\
\hline \multirow[t]{5}{*}{$3 \% \mathrm{HF} / 20 \% \mathrm{HNO}_{3}$} & 5 & $12.1( \pm 2.8)$ & $16.2( \pm 3)$ & $111( \pm 13.3)$ & $0.85( \pm 0.75)$ & $5.79( \pm 1.4)$ & $1.99( \pm 0.21)$ \\
\hline & 10 & $10.7( \pm 1.6)$ & $13.6( \pm 2.1)$ & $89.2( \pm 16.1)$ & $0.23( \pm 0.18)$ & $3.8( \pm 0.5)$ & $1.75( \pm 0.18)$ \\
\hline & 15 & $10.3( \pm 1.3)$ & $12.9( \pm 1.5)$ & $80.1( \pm 11.1)$ & $0.13( \pm 0.18)$ & $3.2( \pm 0.36)$ & $1.5( \pm 0.11)$ \\
\hline & 20 & $7.6( \pm 1.4)$ & $9.9( \pm 1.2)$ & $59.6( \pm 13.7)$ & $-0.23( \pm 0.44)$ & $3.1( \pm 0.4)$ & $1.47( \pm 0.11)$ \\
\hline & 30 & $9.2( \pm 1.6)$ & $11.8( \pm 1.2)$ & $58.9( \pm 19.9)$ & $-0.18( \pm 0.2)$ & $3.41( \pm 0.97)$ & $1.45( \pm 0.15)$ \\
\hline \multirow[t]{5}{*}{$10 \% \mathrm{HF} / 10 \% \mathrm{HNO}_{3}$} & 5 & $4.8( \pm 0.1)$ & $6( \pm 0.14)$ & $27.3( \pm 1.6)$ & $0.085( \pm 0.06)$ & $2.65( \pm 0.07)$ & $1.25( \pm 0.03)$ \\
\hline & 10 & $2.9( \pm 0.8)$ & $3.6( \pm 0.3)$ & $12.7( \pm 2.6)$ & $-0.042( \pm 0.06)$ & $2.85( \pm 0.07)$ & $1.2( \pm 0.04)$ \\
\hline & 15 & $2.5( \pm 0.5)$ & $3.2( \pm 0.7)$ & $13.6( \pm 2.9)$ & $-0.33( \pm 0.91)$ & $2.92( \pm 0.3)$ & $1.14( \pm 0.19)$ \\
\hline & 20 & $3( \pm 1.2)$ & $3.8( \pm 1.5)$ & $15.9( \pm 3.2)$ & $-0.05( \pm 0.15)$ & $3.63( \pm 1)$ & $1.09( \pm 0.04)$ \\
\hline & 30 & $2.2( \pm 0.3)$ & $2.8( \pm 0.6)$ & $15( \pm 2.8)$ & $-0.18( \pm 0.2)$ & $3.6( \pm 0.9)$ & $1.03( \pm 0.06)$ \\
\hline
\end{tabular}

developed surface $S_{w}$, a decrease of $S_{w}$ is observed with the increase of immersion time, from $2.02( \pm 0.07)$ at $5 \mathrm{~min}$ to $1.26( \pm 0.09)$ at $30 \mathrm{~min}$. A bath composition of $3 \% \mathrm{HF} / 20 \%$ $\mathrm{HNO}_{3}$ results in a similar trend. A decrease of roughness is registered from $5 \mathrm{~min}$ to $20 \mathrm{~min}$, with the decrease of $R a$ from $12.1 \mu \mathrm{m}( \pm 2.9)$ down to $7.6 \mu \mathrm{m}( \pm 1.37)$. We observe then an increase of $R a$ at $30 \mathrm{~min}$ with a value of $9.2 \mu \mathrm{m}( \pm$ 1.6). The same trend can be seen for $R q$ although no significant difference is found for $R z$. In terms of surface texture, we notice that for a time lower or equal to $15 \mathrm{~min}$, the surface is mostly composed of peaks, with however a decrease of Rsk. Rsk becomes negative at $t=20 \mathrm{~min}$, revealing the creation of local porosities on the surface. $R k u$ follows the same trend as $R a$, but stays always higher than 3 during all the etching times, showing that sharp asperities remain on the surface. In terms of $S_{w}$, we observe a decrease down to $20 \mathrm{~min}$ at $1.47( \pm 0.11)$. No significant differences are found for $S_{w}$ values between 20 and $30 \mathrm{~min}$. For a bath composition of $10 \% \mathrm{HF} / 10 \% \mathrm{HNO}_{3}$, a significant decrease of roughness is found during the first $5 \mathrm{~min}$, with the decrease of $R a$ down to $4.8 \mu \mathrm{m}( \pm 0.1)$. We observe then a slower decrease of $R a$ down to $2.2 \mu m( \pm 0.3)$ at $30 \mathrm{~min} . R q$ and $S w$ follow the same trend, although no significant differences are found for $R z$ between 15 and $30 \mathrm{~min}$. In terms of surface texture, Rsk keeps being negative during the process, showing an increase of local porosities. This is supported by the increase of $R k u$, until $20 \mathrm{~min}$ where it become higher than 3. This can be interpreted as an increase of asperities with the increase of local porosities.

Figure 9 shows the chemical etching kinetics for different acid bath compositions and times of immersion, via the weight loss and the thickness loss of the surface. The thickness loss parameter corresponds to half the thickness difference between the untreated and the treated sample. We took the half to represent the loss of material on one side of the sample (see Figure 3).

The kinetic of $3 \% \mathrm{HF} / 10 \% \mathrm{HNO}_{3}$ shows a loss of $0.4 \%$ / min of sample mass during the first 5 minutes, corresponding to a loss of $20 \mu \mathrm{m} / \mathrm{min}$ of the surface. After $5 \mathrm{~min}$, we observe a decrease of the reaction speed, with a weight loss of $0.6 \% / \mathrm{min}$ from $10 \mathrm{~min}$ to $30 \mathrm{~min}$, corresponding to a thickness loss of $9 \mu \mathrm{m} / \mathrm{min}$, reaching a weight loss of $16 \%$ ( \pm 


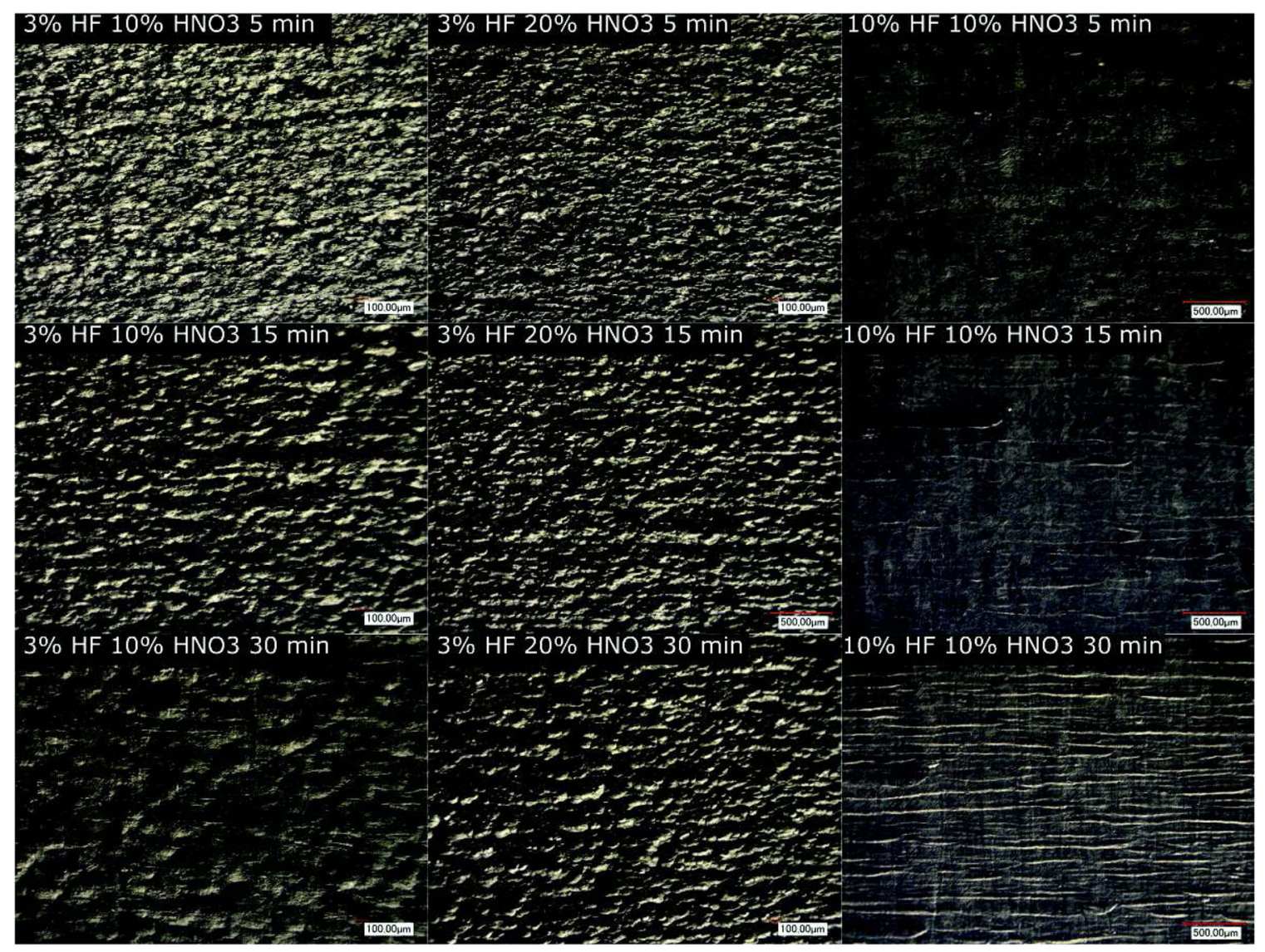

(a) White light microscopy.

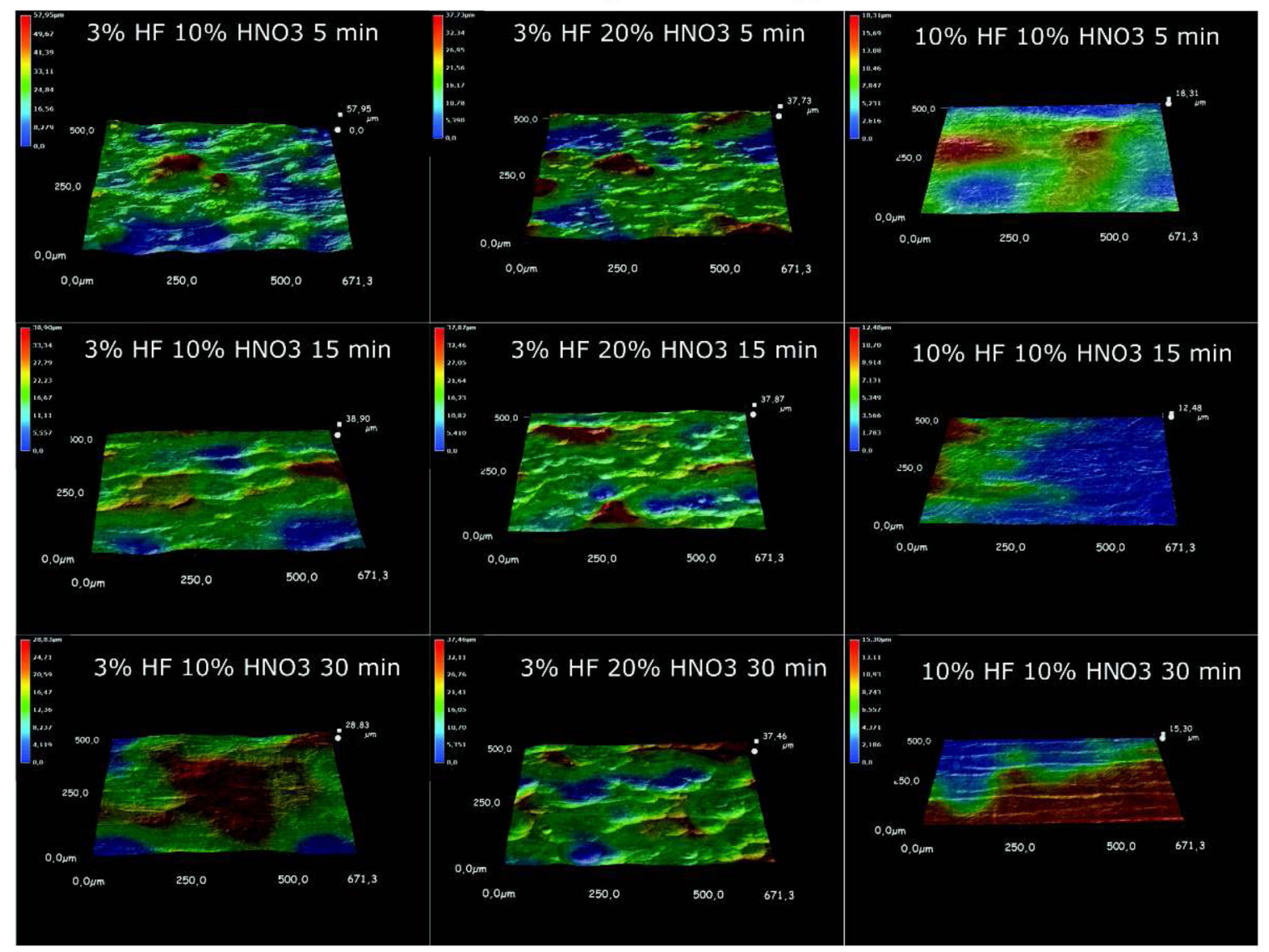

(b) 3D morphologies.

Figure 8. Chemical etching surface for different compositions and durations. Each column represents a composition (from left to right:3\% $\mathrm{HF} / 10 \% \mathrm{HNO}{ }_{3}, 3 \% \mathrm{HF} /$ $20 \% \mathrm{HNO}_{3}, 10 \% \mathrm{HF} / 10 \% \mathrm{HNO}_{3}$ ). Each line represents a time of immersion (from top to bottom: 5, 15, and 30 minutes). 


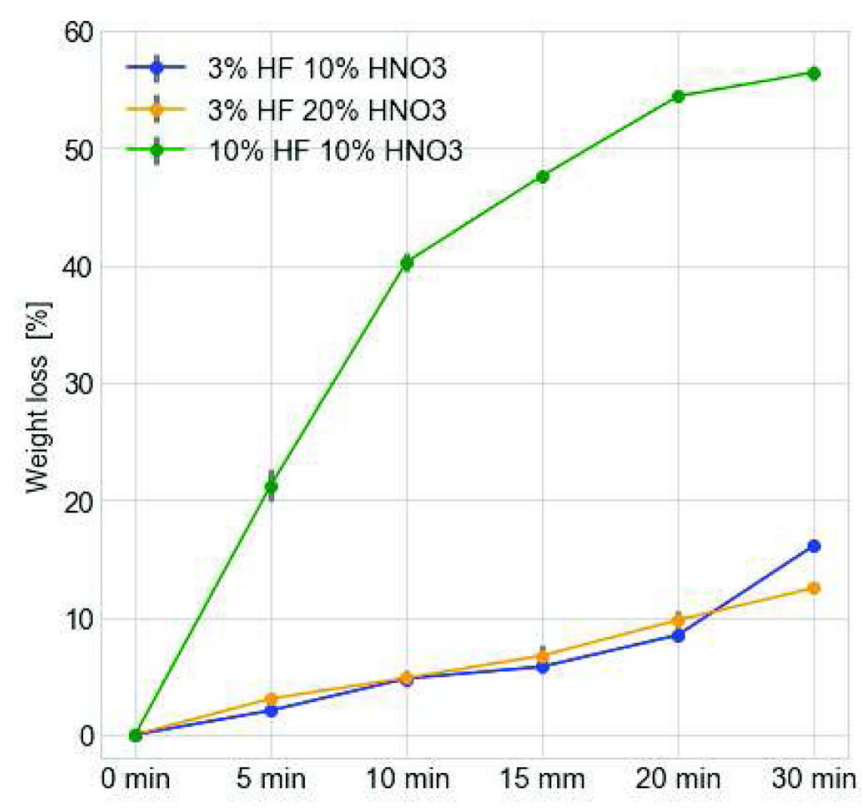

(a) Values of weight loss.

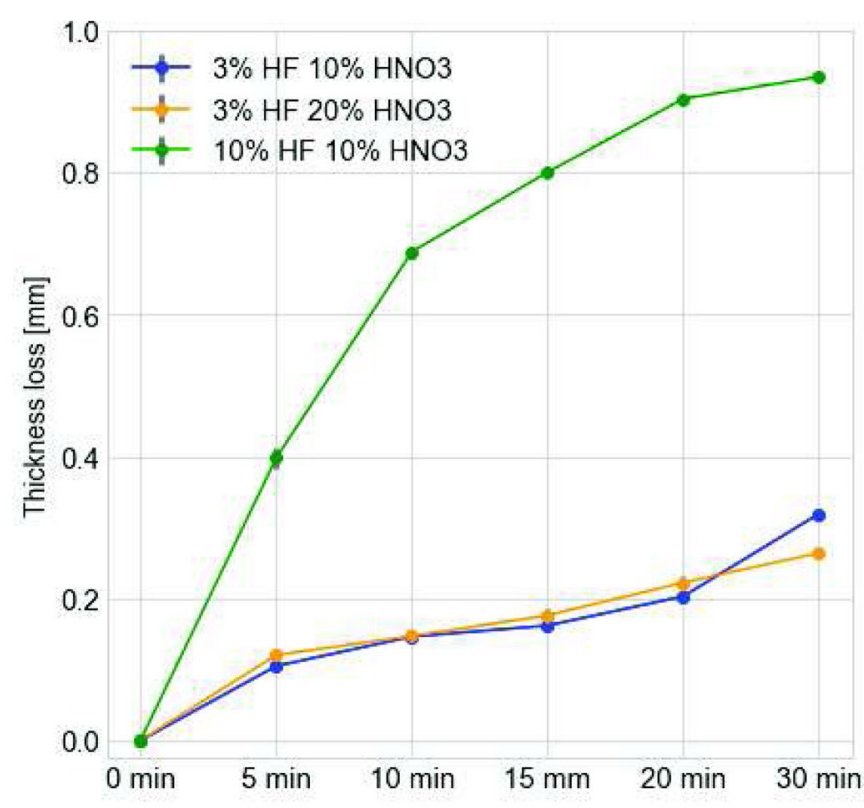

(b) Values of thickness loss.

Figure 9. Weight loss and thickness loss parameters for the different acid bath compositions and durations (green: $10 \% \mathrm{HF} / 10 \% \mathrm{HNO}_{3}$, orange: $3 \% \mathrm{HF} / 20 \%$ $\mathrm{HNO}_{3}$, blue: $3 \% \mathrm{HF} / 10 \% \mathrm{HNO}_{3}$ ).

$0.2)$ and a thickness loss of $319 \mu m( \pm 3)$ at $30 \mathrm{~min}$. The kinetic of $3 \% \mathrm{HF} / 20 \% \mathrm{HNO}_{3}$ follows a similar evolution, with however some differences. A weight loss of $0.6 \% / \mathrm{min}$ during the first 5 minutes is observed, corresponding to a thickness loss of $24 \mu \mathrm{m} / \mathrm{min}$. Then, from $10 \mathrm{~min}$ to $30 \mathrm{~min}$, an average weight loss of $0.4 \% / \mathrm{min}$ is measured, corresponding to a thickness loss of $6 \mu \mathrm{m} / \mathrm{min}$. At $30 \mathrm{~min}$, we reach a weight loss of $12 \%( \pm 0.3)$ and a thickness loss of $264 \mu \mathrm{m}( \pm 3)$. The kinetic of $10 \% \mathrm{HF} / 10 \% \mathrm{HNO}_{3}$ is the most severe, with a weight loss of $4 \% / \mathrm{min}$ during the first 5 minutes, corresponding to a thickness loss of $80 \mu \mathrm{m} / \mathrm{min}$. When passing from 10 to $30 \mathrm{~min}$, we observe then a weight loss of $0.8 \%$ / min, corresponding to a thickness loss of $12 \mu \mathrm{m} / \mathrm{min}$. At $30 \mathrm{~min}$, we obtain a weight loss of $56 \%( \pm 0.6)$ and a thickness loss of $934 \mu m( \pm 6)$.

Figure 10 gives the wetting properties of the etched surfaces, as function of the chemical etching compositions and times of immersion.

Surfaces treated with $3 \% \mathrm{HF} / 10 \% \mathrm{HNO}_{3}$ acid bath show a significant decrease of the $\theta_{a p p}$ during the first 15 minutes, until $48.1^{\circ}( \pm 10.4)$. Then, an increase of $\theta_{\text {app }}$ is registered until $20 \mathrm{~min}$ for a value of $75.8^{\circ}( \pm 5.5)$, followed by a stabilization of the $\theta_{a p p}$ at $30 \mathrm{~min}$ for $76.3^{\circ}$ ( \pm 7.8). Simultaneously, the results show an increase of surface energy up to $90.6 \mathrm{~mJ} / \mathrm{m}^{2}( \pm 11)$ at $15 \mathrm{~min}$, then a decrease down to $61 \mathrm{~mJ} / \mathrm{m}^{2}( \pm 5.2)$ at $20 \mathrm{~min}$. No significant differences are found between the surface energy at 20 and $30 \mathrm{~min}$ $(p=0.89$, Kruskal-Wallis method). For an acid bath of $3 \%$ $\mathrm{HF} / 20 \% \mathrm{HNO}_{3}$, a significant decrease of the $\theta_{a p p}$ is observed during the first 10 minutes, until $44.6^{\circ}( \pm 9.1)$, followed by an increase of $\theta_{\text {app }}$ at $15 \mathrm{~min}$ for a value of $77^{\circ}( \pm 6.7)$. No significant difference is found between 15,20 , and $30 \mathrm{~min}$ $(p=0.5$, Kruskal-Wallis method). Simultaneously, we observe an increase of surface energy up to $95 \mathrm{~mJ} / \mathrm{m}^{2}$ ( \pm
$9.4)$ at $10 \mathrm{~min}$, then a decrease down to $60.6 \mathrm{~mJ} / \mathrm{m}^{2}( \pm 6.4)$ at $20 \mathrm{~min}$. No significant differences are found between the surface energies at 15,20 , and $30 \mathrm{~min}(p=0.15$, KruskalWallis method). The wetting behavior of surfaces treated with $10 \% \mathrm{HF} / 10 \% \quad \mathrm{HNO}_{3}$ acid bath shows a significant decrease of the $\theta_{a p p}$ during the first 5 minutes, until $60.3^{\circ}( \pm$ 4.3), followed by an increase at $10 \mathrm{~min}$ for a value of $65.5^{\circ}$ $( \pm 2.8)$. No significant difference is found between 10,15 , 20 , and $30 \mathrm{~min}(p=0.4, \quad$ Kruskal-Wallis method $)$. Simultaneously, we have an increase of surface energy to $73.9 \mathrm{~mJ} / \mathrm{m}^{2}( \pm 5.2)$ at $5 \mathrm{~min}$, then a decrease at $67 \mathrm{~mJ} / \mathrm{m}^{2}( \pm$ $3.2)$ at $10 \mathrm{~min}$. No significant differences are found between the surface energy at $10,15,20$, and $30 \mathrm{~min}(p=0.4$, Kruskal-Wallis method).

\subsection{Topography VS chemical etching}

\subsubsection{Chemical etching on polished surface}

To assess the effect of the surface original topography on the chemical etching, an analysis on chemical etching on polished surface has been made. To do this, we chose the chemical etching $3 \% \mathrm{HF} / 10 \% \mathrm{HNO}_{3}$ for 5 different immersion times.

Figure 11 and Table 5 show the morphologies and the roughness parameters of SLM-based surfaces polished and treated with chemical etching using protocol $n^{\circ} 2$. Figure 11a shows a reference sample after $15 \mathrm{~min}$ of chemical etching. Taking into account the data from Table 5, the results show that the surface is relatively flat, with however a slight increase of roughness over the time of immersion. $R a$ varies from $0.9 \mu \mathrm{m}( \pm 0.2)$ at the initial state to $1.61 \mu \mathrm{m}( \pm 0.22)$ at $20 \mathrm{~min}$. Then, a decrease at $1.45 \mu \mathrm{m}( \pm 0.1)$ is observed at $30 \mathrm{~min}$. The same trend is observed for $R q$ and $S_{w}$. Also, $R z$ follows the same evolution for the first 15 minutes. 


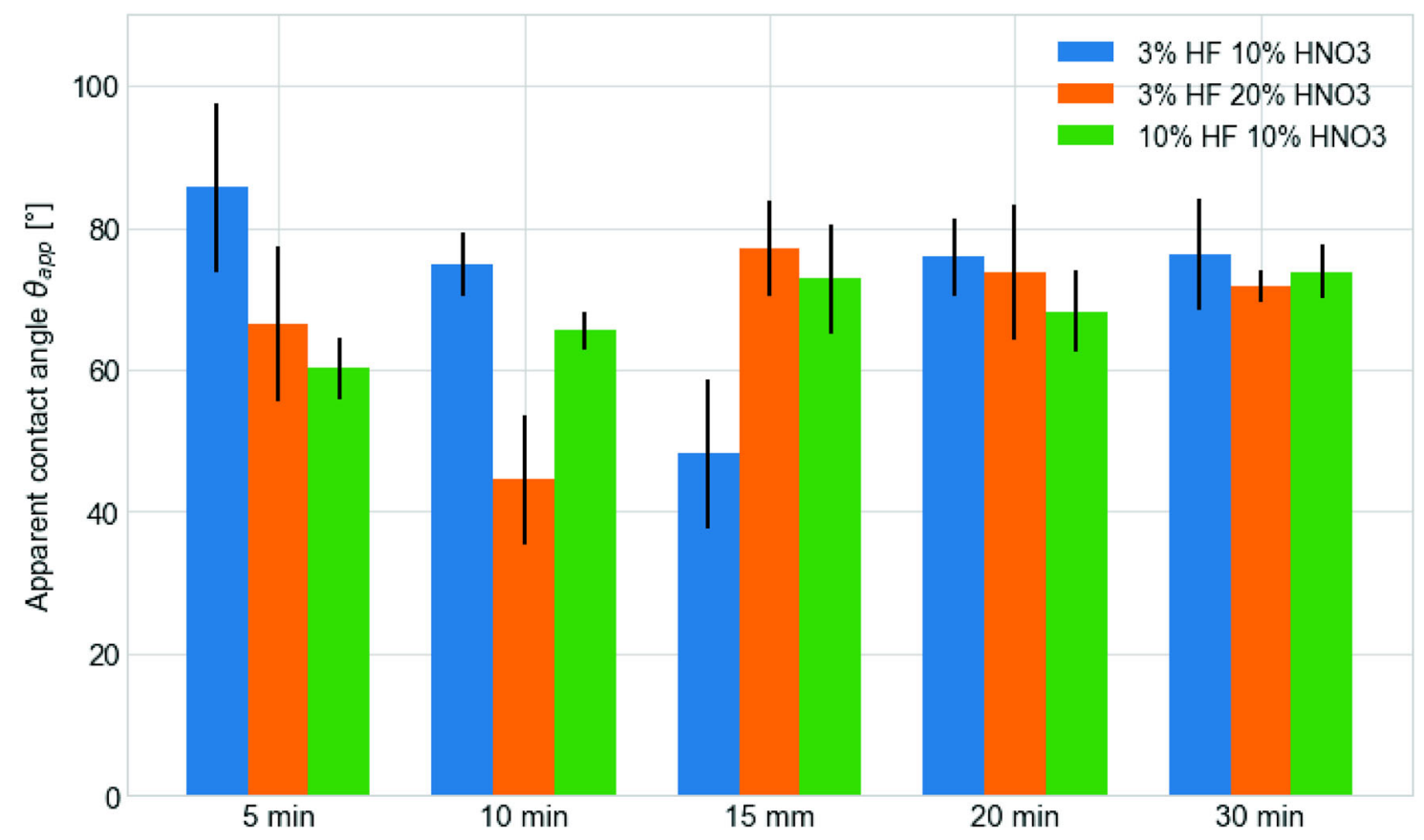

(a) Values of $\theta_{\text {app }}$

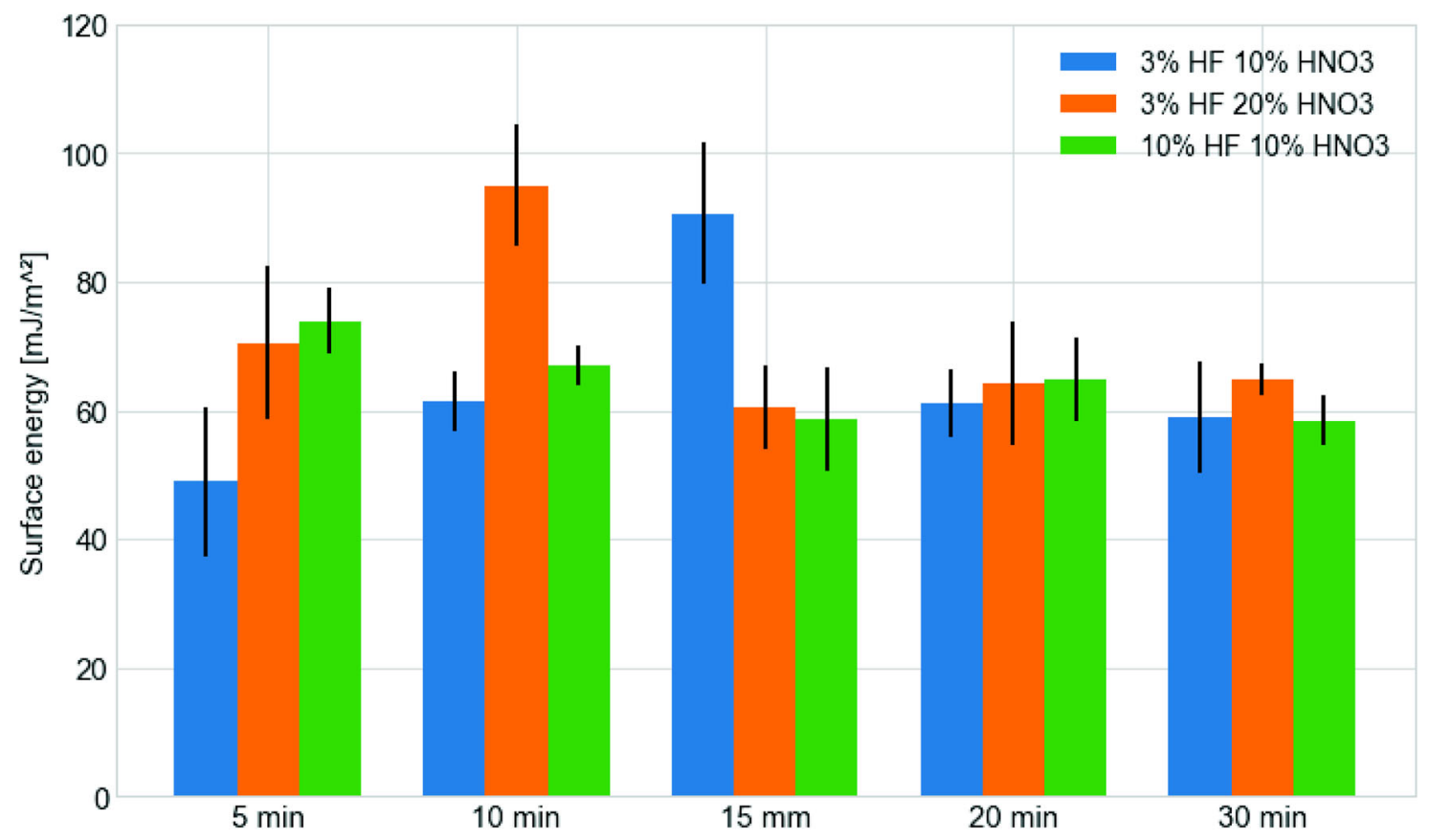

(b) Values of surface energies

Figure 10. $\theta_{\text {app }}$ and surface energies for the different acid bath compositions and durations (green: $10 \% \mathrm{HF} / 10 \% \mathrm{HNO}_{3}$, orange: $3 \% \mathrm{HF} / 20 \% \mathrm{HNO}$, blue: $3 \% \mathrm{HF}$ / $10 \% \mathrm{HNO}_{3}$ ).

However, no significant differences are found for $R z$ between 20 and $30 \mathrm{~min}$. In the same time, Rsk becomes negative after $20 \mathrm{~min}$, revealing the generation of local porosities on flat surface. During all the treatment, an increase of $R k u$ is observed from $3.2( \pm 0.8)$ to $6.2( \pm 2.39)$, revealing an increase of sharp asperities distribution when increasing the immersion time.

In terms of chemical etching kinetics, the evolutions of weight loss and thickness loss presented in Figure 11b and 11c show that we obtain a similar behavior of chemical etching on raw SLM surface (see Figure 9 for 3\% HF/10\% $\mathrm{HNO}_{3}$ ), except during the first 5 minutes. We observe an average weight loss of $0.6 \% / \mathrm{min}$ from 10 to $30 \mathrm{~min}$, corresponding to a thickness loss of $8 \mu \mathrm{m} / \mathrm{min}$. Thus, we can assume that only the very external surface roughness affects the chemical etching kinetic (with type I defects for instance).

In terms of wettability of the surfaces, Figure 12 presents $\theta_{a p p}$ and surface energies for the different times of immersion on polished surfaces. The initial polished surface is 


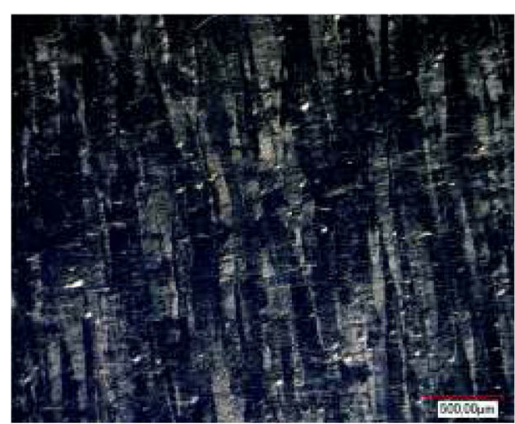

(a) Surface morphology for a chemical etching duration of 15 minutes.

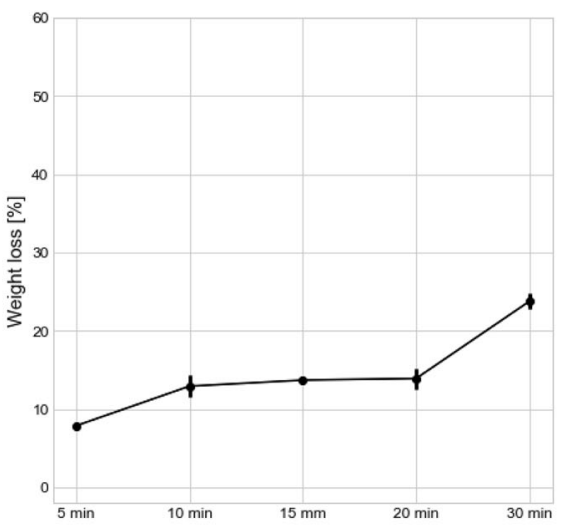

(b) Values of weight loss.

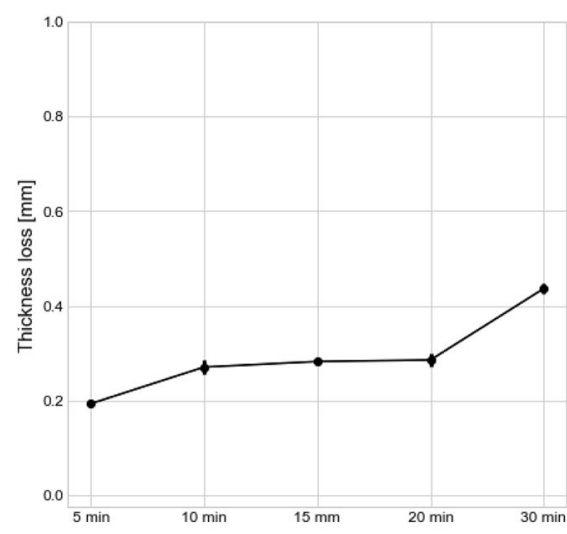

(c) Values of thickness loss.

Figure 11. Results of chemical etching on polished surface for an acid bath composition of $3 \% \mathrm{HF} / 10 \% \mathrm{HNO}_{3}$.

Table 5. Values of roughness parameters for the different etching times.

\begin{tabular}{lcccrrr}
\hline & $R a(\mu \mathrm{m})$ & $R q(\mu \mathrm{m})$ & $R z(\mu \mathrm{m})$ & \multicolumn{1}{c}{$R s k(\mu \mathrm{m})$} & \multicolumn{1}{c}{$R k u(\mu \mathrm{m})$} & \multicolumn{1}{c}{$S_{w}$} \\
\hline untreated & $0.9( \pm 0.2)$ & $1.5( \pm 0.1)$ & $10.1( \pm 1.1)$ & $0.05( \pm 0.01)$ & $3.2( \pm 0.8)$ & $1.01( \pm 0.01)$ \\
$5 \mathrm{~min}$ & $1.12( \pm 0.11)$ & $1.8( \pm 0.38)$ & $10.47( \pm 1.25)$ & $0.02( \pm 0.01)$ & $4.07( \pm 0.05)$ & $1.03( \pm 0.01)$ \\
$10 \mathrm{~min}$ & $1.37 \pm 0.14)$ & $2.2( \pm 0.49)$ & $12.38( \pm 1.19)$ & $0.12( \pm 0.14)$ & $4.25( \pm 0.78)$ & $1.04( \pm 0.01)$ \\
$15 \mathrm{~min}$ & $1.3( \pm 0.13)$ & $2.11( \pm 0.49)$ & $11.03( \pm 1.51)$ & $0.25( \pm 0.14)$ & $5.25( \pm 2.33)$ & $1.06( \pm 0.02)$ \\
$20 \mathrm{~min}$ & $1.61( \pm 0.22)$ & $2.6( \pm 0.64)$ & $16( \pm 1.58)$ & $-0.06( \pm 0.06)$ & $4.95( \pm 1.63)$ & $1.12( \pm 0.02)$ \\
$30 \mathrm{~min}$ & $1.45( \pm 0.1)$ & $2.37( \pm 0.69)$ & $18.57( \pm 3.2)$ & $-1.3( \pm 0.24)$ & $6.2( \pm 2.39)$ & $1.09( \pm 0.02)$ \\
\hline
\end{tabular}

defined by a $\theta_{\text {app }}$ of $78.6^{\circ}( \pm 6)$, corresponding to a surface energy of $52.7 \mathrm{~mJ} / \mathrm{m}^{2}( \pm 6.2)$. No significant differences are found in the $\theta_{\text {app }}$ during the first 15 minutes $(p=0.13$, Kruskal-Wallis method), and the same comments hold for the surface energy. We observe then a decrease of $\theta_{a p p}$ at 20 min with a value of $70^{\circ}$ ( \pm 6.1 ), corresponding to an increase of surface energy up to $64.2 \mathrm{~mJ} / \mathrm{m}^{2}( \pm 6.8)$. Then, at $30 \mathrm{~min}, \theta_{\text {app }}$ increases again up to $75.4^{\circ}( \pm 7.2)$, corresponding to a decrease of surface energy down to $57.5 \mathrm{~mJ} /$ $m^{2}( \pm 7.4)$.

\subsubsection{Chemical etching on specimens at different orienta- tions $\alpha$}

Figure 13 shows the morphology of four SLM-based surfaces fabricated at different inclination (i.e. $\alpha=0^{\circ}, 30^{\circ}, 60^{\circ}$ and $90^{\circ}$ ) and treated with chemical etching using protocol $n^{\circ} 3$. The $3 \mathrm{D}$ morphologies point out the absence of type I defects on all the surface with a decrease of surface amplitude.

The corresponding roughness parameters are depicted in Table 6. $R a$ decreases with the orientation when $\alpha$ passed from $0^{\circ}$ to $60^{\circ}$, whose values vary from $7.88 \mu m( \pm 0.56)$ to $4.79 \mu \mathrm{m}( \pm 0.21)$. Then, $R a$ increases at $\alpha=90^{\circ}$ with the value of $6.51 \mu \mathrm{m}( \pm 1.39)$. The same trend can be observed for $R q$ and $R z$. Rsk assumes negative values for $\alpha=0^{\circ}, 30^{\circ}$, and $90^{\circ}$ whereas at $60^{\circ}, R s k \sim 0$. In addition, $R k u$ is almost equal to 3 for all values of $\alpha$. Compared to the raw surfaces (see Table 3), the application of protocol $n^{\circ} 3$ generates a decrease of sharp peak distribution and an increase of local porosities on all surfaces. However, differences are registered for $S_{w}$, where we observe an increase from $1.3( \pm 0.02)$ at $\alpha=0^{\circ}$ up to $1.35( \pm 0.03)$ at $30^{\circ}$, then a decrease down to
$1.23( \pm 0.06)$ at $90^{\circ}$. By comparing the roughness parameters of Table 6 with those of the raw samples (see Table 3), we register a decrease of $R a$ by $21 \%$ at $\alpha=0^{\circ}$ whereas when $\alpha$ passes from $30^{\circ}$ to $90^{\circ}, R a$ decreases by $\sim 60 \%$. Concerning $S_{w}$, we observe a decrease by $6 \%$ at $\alpha=0^{\circ}$. For $\alpha>30^{\circ}$, we notice an increase of developed surface loss with $\alpha$, from $41 \%$ at $30^{\circ}$ to $62 \%$ at $90^{\circ}$.

In terms of chemical etching kinetics (Figure 14), we measure a thickness loss of $249 \mu m( \pm 24)$ at $\alpha=0^{\circ}$, and $356 \mu m( \pm 19)$ at $30^{\circ}$. Then, a decrease of thickness loss is observed when increasing $\alpha$, until $321 \mu \mathrm{m}( \pm 10)$ at $90^{\circ}$.

The data of $\theta_{a p p}$ from Figure 15, obtained for all the $\alpha$ values, validate the positive effect of the chemical etching on surface wetting. Indeed, all the surfaces become hydrophilic $\left(\theta_{a p p}<90^{\circ}\right)$, independently of $\alpha$. At $\alpha=0^{\circ}$, we obtain a $\theta_{a p p}$ of $51.7^{\circ}( \pm 6.3)$, corresponding to a surface energy of 85.7 $\mathrm{mJ} / \mathrm{m}^{2}( \pm 9.4)$. We observe then an increase of $\theta_{\text {app }}$ at $\alpha=30^{\circ}$, to $75.5^{\circ}$ ( \pm 9.5 ), with a decrease of surface energy down to $57.7 \mathrm{~mJ} / \mathrm{m}^{2}$ ( \pm 9.4). No significant differences are found between the $\theta_{a p p}$ at $\alpha=30^{\circ}, 60^{\circ}$, and $90^{\circ}(p=0.84$, Kruskal-Wallis method). Compared to the raw SLM surfaces, $\theta_{\text {app }}$ decreases by about $32 \%$ at $\alpha=0^{\circ}$ whereas for other values of $\alpha, \theta_{a p p}$ decrease by between $10 \%$ and $20 \%$. Concerning the surface energy, we observe an increase by around $40 \%$ for all the values of $\alpha$, compared to the untreated surfaces (see Figure 5).

\section{Discussion}

This study analyzed the effects of $\mathrm{HF} / \mathrm{HNO}_{3}$ chemical etching compositions and immersion times on the surface topography and wetting for SLM surfaces. 

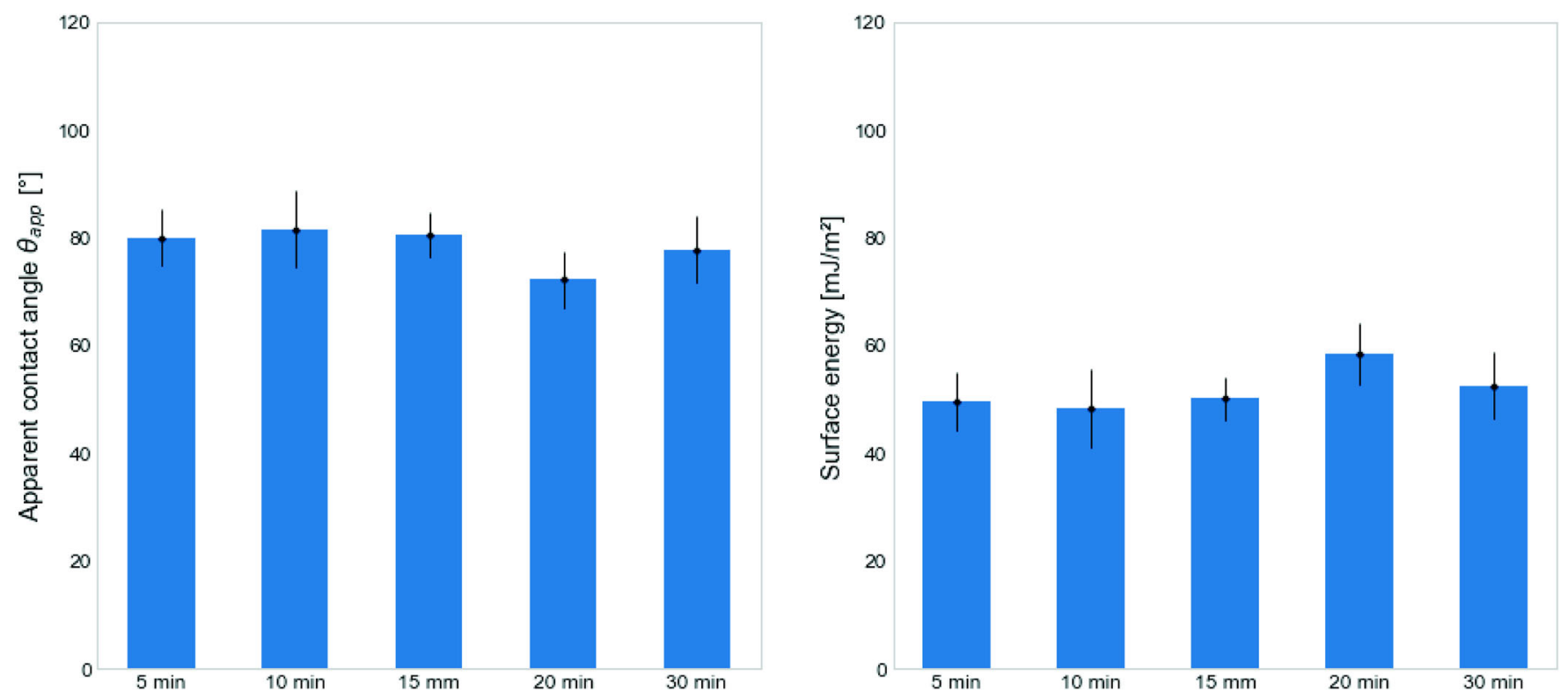

(a) Values of $\theta_{\text {app }}$

(b) Values of surface energies

Figure 12. Values of $\theta_{a p p}$ and surface energies for a chemical etching of $3 \% \mathrm{HF} / 10 \% \mathrm{HNO}_{3}$ on polished surface with different times of immersion.

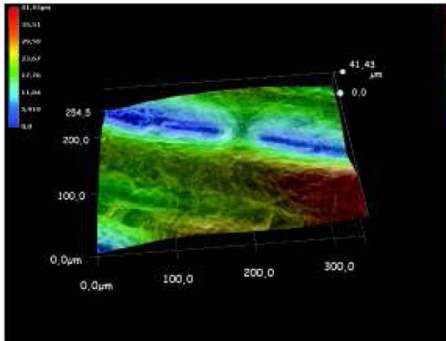

(a) $0^{\circ}$

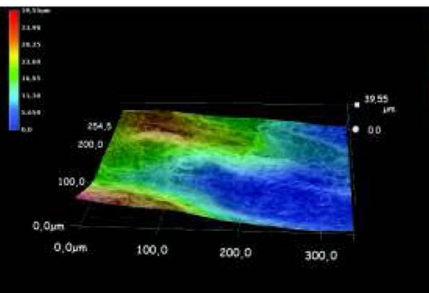

(b) $30^{\circ}$

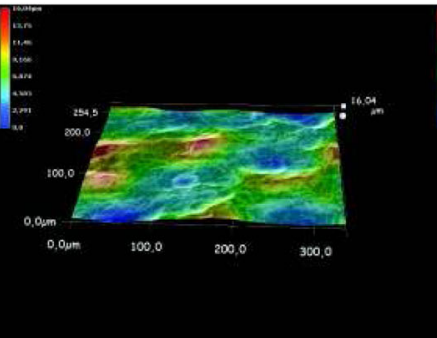

(c) $60^{\circ}$

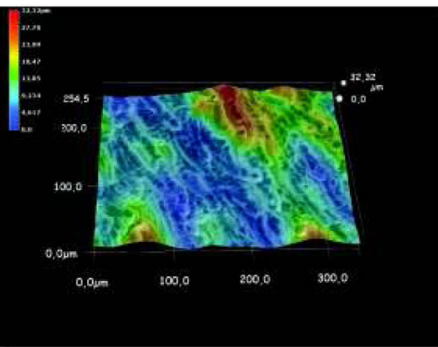

(d) $90^{\circ}$

Figure 13. Surface morphologies of the surface for a chemical etching of $3 \% \mathrm{HF} / 10 \% \mathrm{HNO}_{3}$.

Table 6. Values of roughness parameters depending on $\alpha$.

\begin{tabular}{llllrr}
\hline & $R a(\mu m)$ & $R q(\mu m)$ & $R z(\mu m)$ & \multicolumn{1}{c}{$R s k(\mu m)$} & \multicolumn{1}{c}{$S_{w}$} \\
\hline $0^{\circ}$ & $7.88( \pm 0.56)$ & $9.55( \pm 0.7)$ & $36.24( \pm 8.24)$ & $-0.077( \pm 0.14)$ & $3.08( \pm 0.71)$ \\
$30^{\circ}$ & $6.34( \pm 0.34)$ & $7.41( \pm 0.36)$ & $41.70( \pm 2.23)$ & $-0.3( \pm 0.06)$ & $3.11( \pm 0.24)$ \\
$60^{\circ}$ & $4.79( \pm 0.21)$ & $5.61( \pm 0.16)$ & $32.67( \pm 2.7)$ & $0.13( \pm 0.17)$ & $2.92( \pm 0.28)$ \\
$90^{\circ}$ & $6.51( \pm 1.39)$ & $7.76( \pm 1.64)$ & $40.65( \pm 4.03)$ & $-0.03( \pm 0.22)$ & $1.35( \pm 0.03)$ \\
\hline
\end{tabular}

\subsection{Remarks on surface roughness parameters}

The analysis of raw SLM surface topographies pointed out significant differences depending on the printing orientation angle $\alpha$. The surface roughness parameters $(R a, R q, R z$, and $S_{w}$ ) increased with $\alpha$ (see Table 3). Especially, the increase of Rsk from negative to positive values when augmenting $\alpha$ proved to be a measure of increasing peak distributions due to the higher number of sintered particles trapped in the surface. These topographic variations were the results of different types of surface defects: type II defects (the melting bed texture and the staircase effect) and type I defects (the sintered particles trapped in the surface) [16]. Type I defects on the surface were assumed to cause the hydrophobic properties of the SLM surface. Indeed, excepted $\alpha=0^{\circ}$, our results (Figure 5) showed $\theta_{a p p}$ superior to $90^{\circ}$ for all the other orientations in agreement with the presence of type I defects on the surface. These results agreed with different studies of the literature [41, 42].

Three different $\mathrm{HF} / \mathrm{HNO}_{3}$ chemical etchings had been considered, and they proved to have significant effects on the surface topography and wetting. Indeed, the surface roughness parameters showed a progressive decrease with the duration of the chemical etching for all the compositions. For the chemical etching 3\% HF/10\% $\mathrm{HNO}_{3}$, we observed a continuous decrease of roughness parameters ( $R a, R q$, and $R z$ ) down to 30 min whereas the same parameters stopped decreasing at $20 \mathrm{~min}$ for the chemical etching $3 \% \mathrm{HF} / 20 \% \mathrm{HNO}_{3}$, followed by an increase of roughness (see Table 4). The chemical etching $10 \% \mathrm{HF} / 10 \% \mathrm{HNO}_{3}$ generated a higher roughness decrease, down to around $2 \mu \mathrm{m}$ at $30 \mathrm{~min}$. This outcome suggests that the proportion in HF controls the power of the reaction, and so the roughness reduction, whereas the proportion in $\mathrm{HNO}_{3}$ controls 
the speed of the reaction (results validated in the literature [43]). The skewness value (Rsk) was positive for the nonetched sample, due to a predominance of peaks in the surface. After the different etchings, a decrease of skewness proportional to etching duration was observed for all the different compositions. $3 \% \quad \mathrm{HF} / 10 \% \quad \mathrm{HNO}_{3}$ showed a decrease of $R s k$ and $R k u$ down to $30 \mathrm{~min}$ where a negative value was observed, whereas negative values appeared at 20 min for $3 \% \mathrm{HF} / 20 \% \mathrm{HNO}_{3}$. $10 \% \mathrm{HF} / 10 \% \mathrm{HNO}_{3}$ showed negative values of Rsk since the first $5 \mathrm{~min}$ and an increase of Rku. These results highlight that the chemical etching decreases the peak distribution density during the first phase, then it creates local porosities on the surface. The weight loss varied depending on the chemical compositions and the times of immersion (see Figure 9). For all the compositions, high weight losses were observed during the initial phase (first 5 minutes), followed by a high thickness loss.

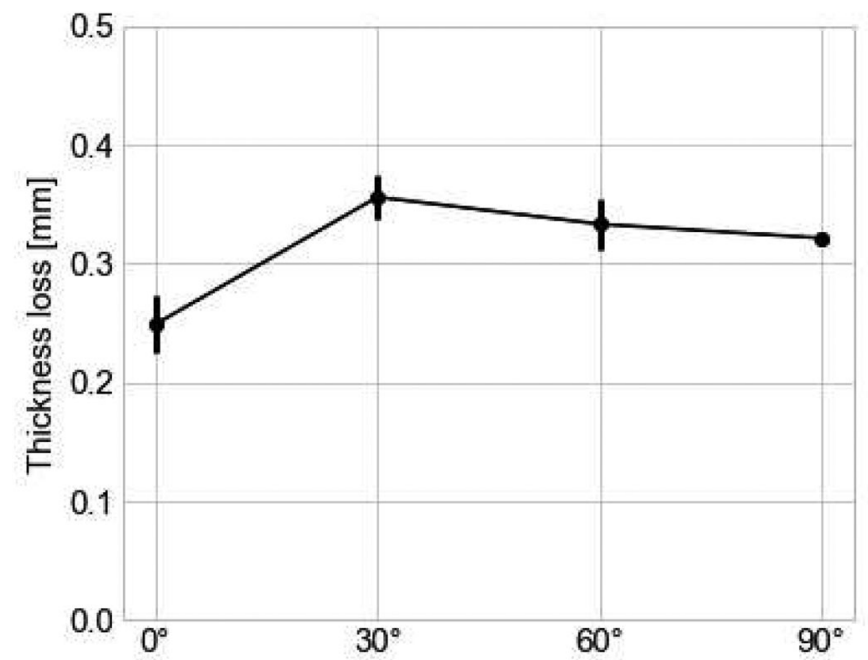

Figure 14. Thickness loss of surfaces for a chemical etching of $3 \% \mathrm{HF} /$ $10 \% \mathrm{HNO}_{3}$.

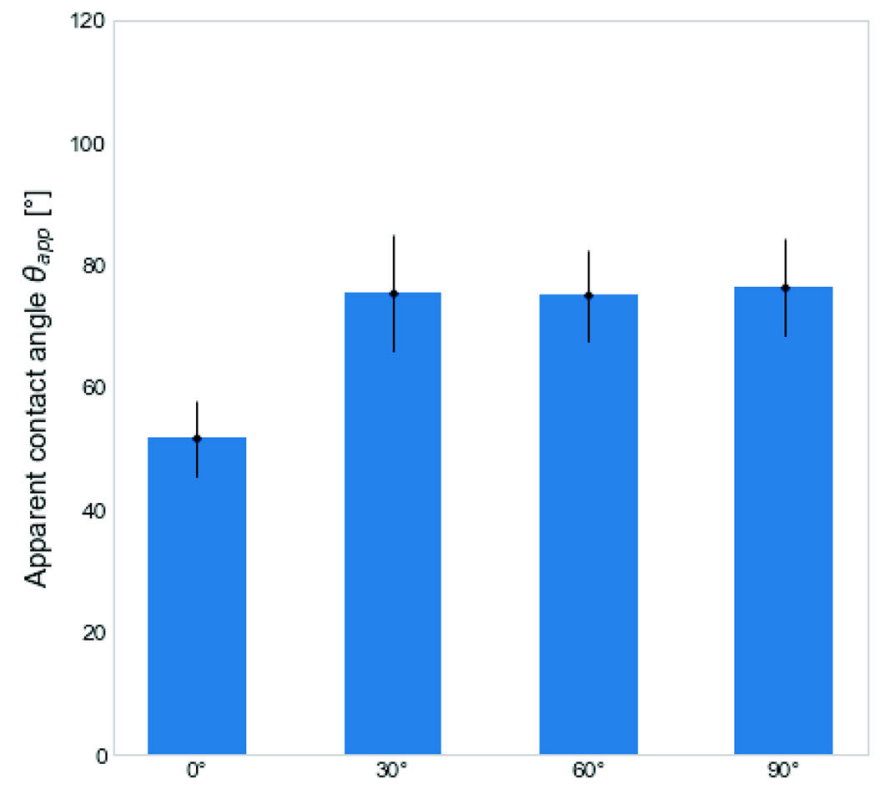

(a) Values of $\theta_{\text {app }}$.
This can be explained by the high quantity of reactives at the initial state, but also by the external layer of material which is very rough (equivalent to a homogeneous layer of titanium alloy material with a lower density). 3\% HF/10\% $\mathrm{HNO}_{3}$ and $3 \% \mathrm{HF} / 20 \% \mathrm{HNO}_{3}$ showed similar weight loss and thickness loss until $t=20 \mathrm{~min}$. After, $3 \% \mathrm{HF} / 10 \%$ $\mathrm{HNO}_{3}$ showed a higher etching rate. This was reflected on the parameter $S_{w}$ which decreased monotonically until 30 min (see Table 4). $10 \% \mathrm{HF} / 10 \% \mathrm{HNO}_{3}$ showed the highest etching rate with a corresponding weight loss of $60 \%$ and the highest decrease of $S_{w}$. In terms of wetting properties, the contact angle $\theta_{a p p}$ was reduced on etched samples. Indeed, for all the compositions, the initial phase $(t=5 \mathrm{~min})$ was followed by a decrease of $\theta_{a p p}$ and an increase of surface energy, with the disappearance of the type I defects (i.e. sintered particles) (see Figure 10). $3 \% \mathrm{HF} / 10 \% \mathrm{HNO}_{3}$ composition generated a decrease of $\theta_{a p p}$ until $t=15 \mathrm{~min}$, then the value increased and stabilized at $t=30 \mathrm{~min}$. The same behavior was observed for $3 \% \mathrm{HF} / 20 \% \mathrm{HNO}_{3}$ composition. However, in this last case, the minimum value of $\theta_{a p p}$ was reached faster than the previous one due to the higher proportion of $\mathrm{HNO}_{3}$. If we compare our results to the literature, the trends described beforehand match those of several published papers. Wysocki et al. [42] studied the effect of chemical etching of SLM surfaces using a solution of $2.2 \%$ $\mathrm{HF} / 20 \% \mathrm{HNO}_{3}$. The authors observed a decrease of $\theta_{\text {app }}$ from around $100^{\circ}$ at $t=0 \mathrm{~min}$ to around $45^{\circ}$ after $6 \mathrm{~min}$. In our case, the composition $3 \% \mathrm{HF} / 20 \% \mathrm{HNO}_{3}$ followed the same behavior, even if the reduction of $\theta_{a p p}$ was less pronounced. However, results relative to longer etching times have not be reported in [42]. In our study, for a time greater than $5 \mathrm{~min}, 10 \% \mathrm{HF} / 10 \% \mathrm{HNO}_{3}$ composition generated an increase of $\theta_{a p p}$ followed by a stable phase. This makes us assume that the minimum of $\theta_{a p p}$ was reached during the initial phase.

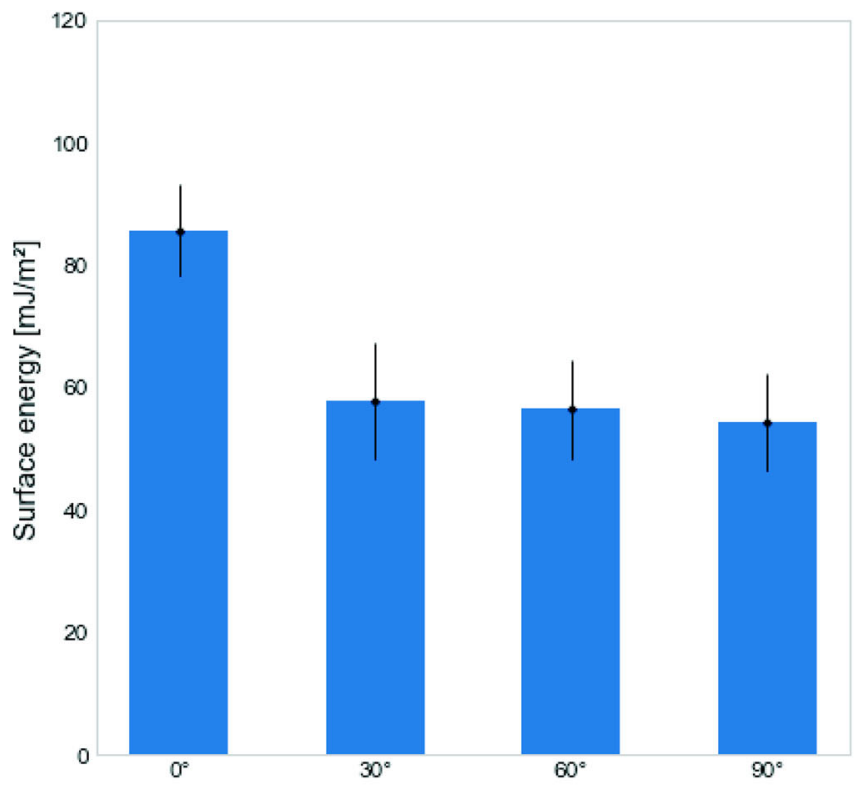

(b) Values of surface energies.

Figure 15. Values of $\theta_{a p p}$ and surface energies for a chemical etching of $3 \% \mathrm{HF} / 10 \% \mathrm{HNO}_{3}$ depending on $\alpha$. 


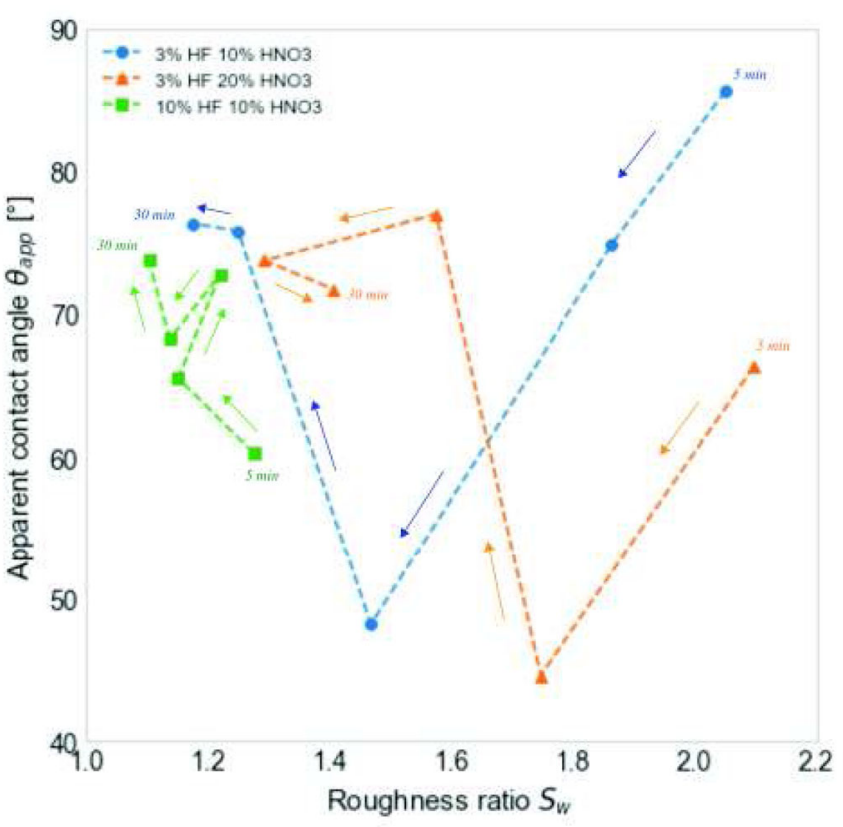

Figure 16. The relationship between apparent contact angle and roughness ratio for the SLM surfaces etched with different bath compositions (3\% HF/10\% $\mathrm{HNO}_{3}$ in blue, $3 \% \mathrm{HF} / 200 \% \mathrm{HNO}_{3}$ in red, $10 \% \mathrm{HF} / 10 \% \mathrm{HNO}_{3}$ in green) at different immersion times. The arrows show the increase of the time of chemical etching.

\subsection{Surface properties and wetting model}

Wettability is defined as the thermodynamic interface equilibrium between the liquid, solid, and gas phases. Thus, $\theta_{\text {app }}$ variation can be provoked by the modifications of the solid phase, the two other phases being constant. These modifications can be of different nature: chemical, topographical, mechanical, etc. In particular, the roughness is proved to have a significant influence on the wettability $[39,40]$. The results obtained in this study showed that the roughness is an important factor to be considered in the wetting behavior of surfaces. The initial roughness decrease was shown to be related to the elimination of type I defects (see Figure 8), causing a decrease of $\theta_{a p p}$. A further decrease of $\theta_{a p p}$ was observed with changes in topography (see Figure 8 and Table 4), followed by a stabilization for $10 \% \mathrm{HF} / 10 \% \mathrm{HNO}_{3}$ or an increase for $3 \% \mathrm{HF} / 10 \% \mathrm{HNO}_{3}$ and $3 \% \mathrm{HF} / 20 \%$ $\mathrm{HNO}_{3}$. In order to determine the evolution of wetting behavior of the surface during chemical etching, experimental data can be analyzed using wetting models taken from literature. The most classical model evaluating the apparent contact angle as function of the roughness is the Wenzel model [44]. According to this model, the roughness is considered through the introduction of the "roughness ratio" as the ratio between the actual surface and the projected one. Thus, the apparent contact angle $\theta_{a p p}$ is calculated as the product between the the roughness ratio $S_{w}$ and the intrinsic contact angle $\theta_{\gamma}$ :

$$
\cos \theta_{\text {app }}=S_{w} \cdot \cos \theta_{\gamma}
$$

The Wenzel model, however, applies only when a perfect contact is ensured between an homogeneous solid surface and the liquid. Since for a given solid/liquid material combination the intrinsic contact angle $\theta_{\gamma}$ does not depend on
$S_{w}$, eq. 4 states that when $\theta_{\gamma}<90^{\circ}$, the higher the roughness (thus the higher $S_{w}$ ), the lower $\theta_{a p p}$. On the contrary, if $\theta_{\gamma}>$ $90^{\circ}$, the higher the roughness, the higher $\theta_{a p p}$.

Concerning the wetting nature of flat TA6V surfaces, the experimental measurements suggest that the surface is hydrophilic, see $[45,46]$. However, beyond the surface roughness effect, the SLM process as well as the chemical etching could let vary material properties and chemical composition of the surface, respectively. Indeed, concerning SLM process, an analysis of the material behavior has shown the presence of a gradient of hardness (Figure 6) from the external border of the specimen to the internal core. This material gradient was followed by a gradient of wetting properties at different depths within the specimen (see Figure 7), more precisely, with a decrease of $\theta_{a p p}$ from the external border to the internal core. This phenomenon could be the result of a faster cooling time of the material on the borders compared to the one of the core. Several works of literature had already shown an increase of hardness on materials submitted to slower cooling process [47], via a heat treatment, followed by a decrease of $\theta_{a p p}$ compared to the material without heat treatment [41]. Finally, it can be assumed that the SLM process is not a factor that could change the wetting properties of the surface toward hydrophobicity. On the other hand, concerning chemical etching effect in terms of chemical composition of the solid surface, titanium surfaces treated by acid hydrofluoric HF have shown changes in their wetting properties. Zahran et al. studied the wetting properties of titanium surfaces treated with HF. They explained that if the chemical changes affected the decrease of $\theta_{a p p}$ during the first $3 \mathrm{~min}$, the most influencing parameters for longer immersion times were the roughness parameters via the form and the distribution of the peaks. Taking into account this literature results, we can assume that flat TA6V surfaces obtained by SLM and treated chemically exhibit hydrophilic properties.

Figure 16 presents the evolution of $\theta_{\text {app }}$ as a function of $S_{w}$ and at the five different immersion times $(5,10,15,20$ and $30 \mathrm{~min}$ ). The straight lines and arrows indicate the direction of increasing immersion time. For each one of the applied chemical compositions, a global decrease is observed for low values of $S_{w}$ which correspond to high values of immersions time. These parts follow the trend provided by the Wenzel's model. Moreover, this result is supported by the fact that at those values of immersion time the variation of chemical composition of the surface is negligible. On the other hand, in the case of $3 \% \mathrm{HF} / 10 \%$ $\mathrm{HNO}_{3}$ and $3 \% \mathrm{HF} / 20 \% \mathrm{HNO}_{3}$, an increase of $\theta_{\text {app }}$ is observed for high values of $S_{w}$ (i.e. beyond 1.41 and 1.75 , respectively). This values of $S_{w}$ correspond to brief immersion times wherein the chemical composition variation of the surface could be considerable. This suggests that, at those stages, the $\theta_{\gamma}$ could vary due to chemical composition variation. Otherwise, these results mean that the Wenzel's model is no longer applicable and the hypothesis of full contact is not valid at high $S_{w}$.

If the Wenzel's model no longer applies, the influence of the roughness can be described by a more general model: 


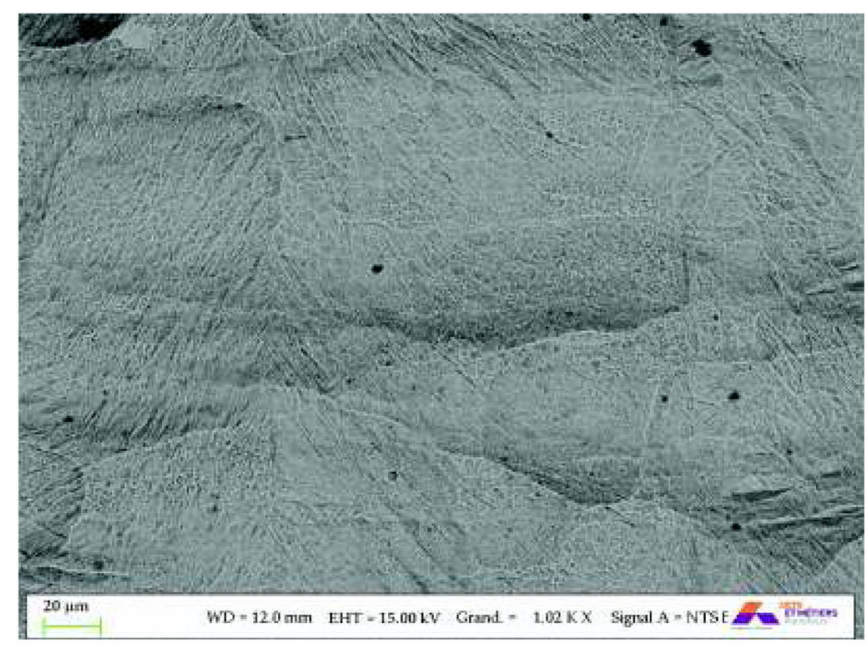

(a) $3 \% \mathrm{HF} / 10 \% \mathrm{HNO}_{3}$

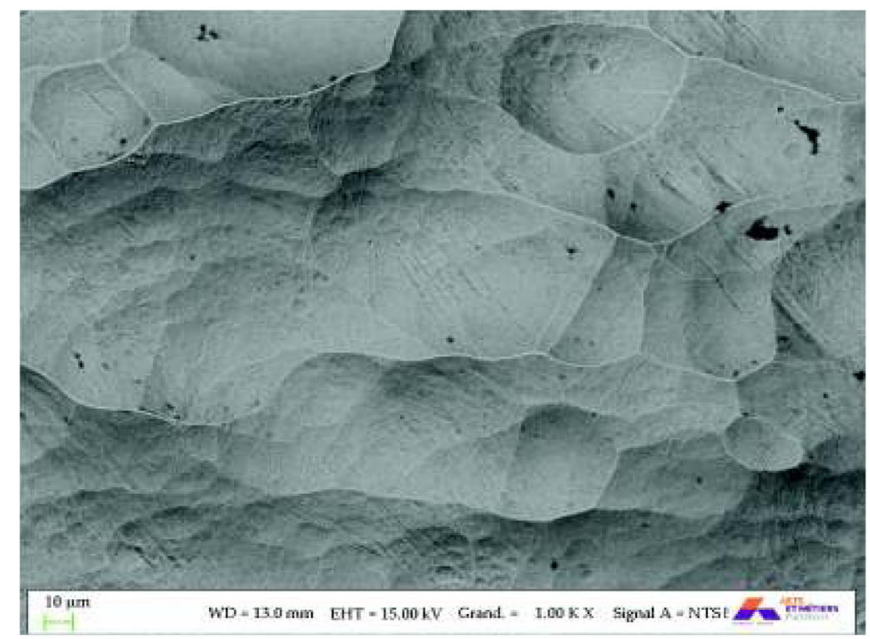

(b) $3 \% \mathrm{HF} / 20 \% \mathrm{HNO}_{3}$

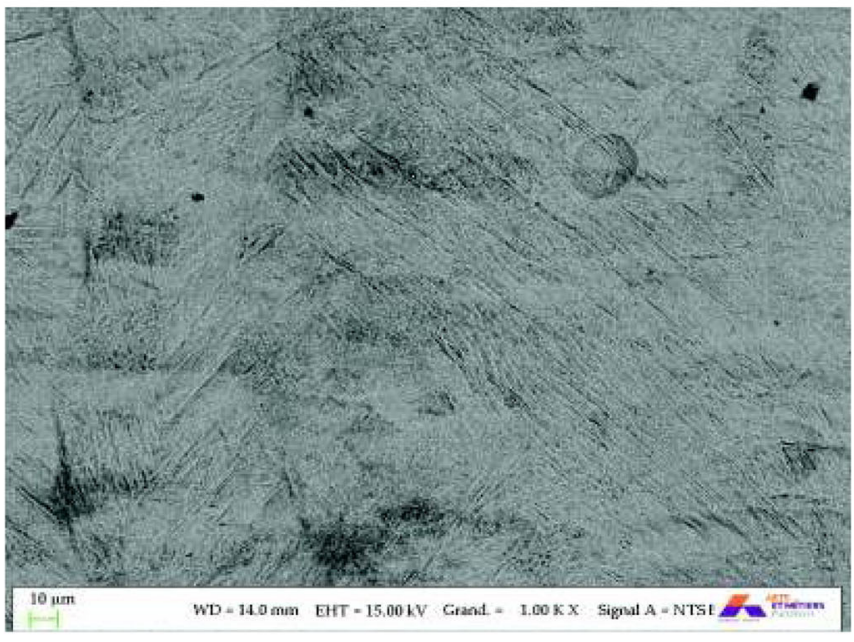

(c) $10 \% \mathrm{HF} / 10 \% \mathrm{HNO}_{3}$

Figure 17. SEM image of the surface condition in BSD for a chemical etching of 15 minutes.

the Cassie-Baxter's model [48]. In the Cassie-Baxter's model, the drop is assumed to not fully fill the surface and that small pockets of air stay between the drop and the surface. Thus, we obtain a mix of solid-liquid-gas contact surface satisfying the thermodynamic equilibrium. Thus, Cassie and Baxter defined a model relating $\theta_{\gamma}$ to $\theta_{a p p}$ via the fractional area of solid material $f_{s}$ with respect to the whole contact area [48], expressed as:

$$
\cos \theta_{a p p}=f_{s} \cdot\left(1+\cos \theta_{\gamma}\right)-1
$$

It can be assumed that an increase of the roughness results in the increase of air pockets on the surface. Thus, this decreases the fractional area $f_{s}$. Therefore, the higher the roughness (thus the higher $S_{w}$ ), the higher $\theta_{\text {app }}$. This behavior, predicted by Cassie-Baxter's model, is in agreement with the results of $3 \% \mathrm{HF} / 10 \% \mathrm{HNO}_{3}$ and $3 \% \mathrm{HF} / 20 \% \mathrm{HNO}_{3}$ at high values of $S_{w}$ (i.e. equal or higher to 1.41 and 1.75 respectively). This means that, very probably, at high $S_{w}$ some porosities appear at the solid/liquid contact surface.

Thanks to results of Figure 16 and taking into account literature results, we can assume that different wetting regimes take place on SLM surfaces during the chemical etching. If we consider the chemical composition $3 \% \mathrm{HF} / 10 \% \mathrm{HNO}_{3}$, we observe a first phase at $S_{w}>1.41$ where the roughness is very probably (since no porosity observation has been conducted) high enough to trap air pockets at the solid/liquid interface. Thus, the Cassie-Baxter's model applies with a decrease of the apparent contact angle as the roughness decrease. For $S_{w}<1.41$, the air pockets leave the surface as the roughness decreases. Thus, the wetting regime follows the Wenzel's model with an increase of the contact angle as the roughness decrease. The same behavior can be observed on $3 \% \mathrm{HF} / 20 \% \mathrm{HNO}_{3}$ chemical composition, with no significant differences observed for $S_{w}<1.5$. The chemical composition $10 \% \mathrm{HF} / 10 \% \mathrm{HNO}_{3}$ globally follows the Wenzel's model, with the presence of the speak due to the measurement variability. Some studies propose further models for the case of wetting regimes switching from the Wenzel's model to the Cassie-Baxter's one. We can mention the model of Nagayama et al. [49] that proposed a partial wetting model for nano/microstructured surfaces. However, for the sake of brevity, no further models will be analyzed in the present work. 


\subsection{Remarks on biocompatibility}

To conclude, in order to remove type I defects (sintered particles), all analyzed chemical compositions are sufficient with an immersion time lower or equal to $5 \mathrm{~min}$. In terms of wettability, $3 \% \mathrm{HF} / 10 \% \mathrm{HNO}_{3}$ composition generated the highest surface energy after an immersion time of $15 \mathrm{~min}$ (see Figure 10). $10 \% \mathrm{HF} / 10 \% \mathrm{HNO}_{3}$ gave a lower value of the maximum of surface energy but we could assume that the maximum of surface energy was reached before the $5 \mathrm{~min}$. However, its surface energies gave better values than the two other compositions for longer times. The surface roughness of $10 \% \mathrm{HF} / 10 \% \mathrm{HNO}_{3}$ composition was the fastest one to reduce roughness and gave the lowest roughness values $(R a=2 \mu \mathrm{m}$ at $t=30 \mathrm{~min})$. On the contrary, when using 3\% $\mathrm{HF} / 20 \% \mathrm{HNO}_{3}$, the minimum value of $\mathrm{Ra}$ was $7.9 \mu \mathrm{m}$ and increased again after some time. $3 \% \mathrm{HF} / 10 \%$ $\mathrm{HNO}_{3}$ composition generated a minimum value of $\mathrm{Ra}$ lower than $7 \mu \mathrm{m}$, with a homogeneous etching. This composition improved surface quality and wettability of all surfaces at different $\alpha$ (see Figures 13 and 15, and Table 6). Only 10\% $\mathrm{HF} / 10 \% \mathrm{HNO}_{3}$ composition for an immersion time of 30 min filled the objectives of the work in terms of surface roughness. However, this set of parameters presents challenging issues: (i) The weight loss reached to $60 \%$ with more than $20 \%$ of weight lost during the first 5 minutes, corresponding to a thickness loss of $400 \mu \mathrm{m}$. This effect has to be taken into account in the design of the component in terms of tolerance dimensions. (ii) The reaction was really powerful and caused the creation of a lot of $\mathrm{NO}_{2}$ gas in the solution. This could be a problem for complex geometries were the gas could stuck on the internal surface and prevent a homogeneous etching [37]. In the same way, the reaction can be heterogeneous and create a lot of porosity on the surface. (iii) We observed the creation of a layer of oxide after a certain time. It can be a hindrance for biomedical applications. (iv) The reaction created cracks on a certain number of samples. This can be the combination of the powerful reaction with the residual stress, and thus can be prevented by heat treatment. Besides, if we look at 3\% HF/ $10 \% \mathrm{HNO}_{3}$ and $3 \% \mathrm{HF} / 20 \% \mathrm{HNO}_{3}$ surfaces, we noticed that at the sub-micron scale, the surface were relatively flat (see Figure 17) and that most of the roughness was present at a sub-meso scale. So, if we compare to other studies in the biomedical field where surface energy and wetting are drastically altered on nanometer (less than $100 \mathrm{~nm}$ ) and submicron (greater than $100 \mathrm{~nm}$ ) scales [30], those surfaces could be considered as viable.

\section{Conclusion}

In the present work, the effect of the chemical etching to improve the topography and the wettability of SLM-based surfaces has been analyzed. First, raw SLM surfaces of samples printed at different inclinations $\alpha$ (with respect to the printing plateau) have been observed. Moreover, the gradient of material properties of specimens (due to SLM process) has also been evaluated. Then three different surface treatment protocols have been applied on both raw and polished samples. The results showed that raw SLM surfaces orientated at $\alpha>0^{\circ}$ exhibited hydrophobic properties, due to sintered particles (type I defects) trapped into the surface. The analysis of surfaces treated with three chemical etching compositions and five different immersion times have shown an elimination of type I defects followed by an increase of wetting properties. The three etching compositions reached a minimum apparent contact angle $\theta_{a p p}$ for different immersion times. The analysis of the surface wetting showed that the key factor to improve this property is the surface roughness. The comparison of literature wetting models provided some explanations on the influence of the roughness as function of chemical etching composition and times. Furthermore, there are also second-order factors. Indeed, surface wetting is also influenced by the variation of material properties. The biomedical application of integrated implants has been selected as target to attain specific ranges of surface roughness and wettability (through the proposed surface treatments). Results show that the main requirements of wetting were met but not the conditions of average roughness. Therefore it can be assessed that chemical etching is a suitable surface treatment to improve biocompatibility of SLM-based implants. However further studies could let analyze similar chemical compositions in order to reach simultaneously both requirements on surface wetting and average roughness.

\section{Funding}

The first author is grateful to ENSAM Fundation for supporting this research work through the RNC Santé of Arts et Métiers Science and Technology engineering school. Specimens were produced on the Futurprod Additive Manufacturing Plateform of I2M Institute (Bordeaux, France).

\section{ORCID}

A. Catapano (iD http://orcid.org/0000-0002-0504-1624

M. Mesnard (iD) http://orcid.org/0000-0002-6920-7662

\section{References}

[1] M. Jimenez, L. Romero, I.A. Dominguez, M. del Mar Espinosa, and M. Dominguez, Additive manufacturing technologies: an overview about 3D printing methods and future prospects, Complexity, vol. 2019, pp. 1-30, 2019. DOI: 10.1155/2019/ 9656938.

[2] Abid Haleem and Mohd Javaid, 3D printed medical parts with different materials using additive manufacturing, Clin. Epidemiol. Global Health, vol. 8, no. 1, pp. 215-223, 2020. DOI: $10.1016 /$ j.cegh.2019.08.002.

[3] C. Y. Yap, C. K. Chua, Z. L. Dong, Z. H. Liu, D. Q. Zhang, L. E. Loh and S. L. Sing, Review of selective laser melting: materials and applications, Appl. Phys. Rev., vol. 2, no. 4, pp. 041101, 2015. DOI: $10.1063 / 1.4935926$.

[4] Pacurar Razvan and Pacurar Ancuta, Applications of the selective laser melting technology in the industrial and medical fields, New Trends 3D Print., Igor V Shishkovsky, IntechOpen, 2016. DOI: $10.5772 / 63038$.

[5] M. Nurhaniza, M.K.A.M. Ariffin, F. Mustapha, and B.T.H.T. Baharudin, Analyzing the effect of machining parameters 
setting to the surface roughness during end milling of CFRPaluminium composite laminates, Int. J. Manuf. Eng., vol. 2016, pp. 1-9, 2016. DOI: 10.1155/2016/4680380.

[6] M. Alauddin, M.A. El Baradie, and M.S.J. Hashmi, Computeraided analysis of a surface-roughness model for end milling, J. Mater. Process. Technol., vol. 55, no. 2, pp. 123-127, 1995. DOI: 10.1016/0924-0136(95)01795-X.

[7] Du-Ming Tsai and Chi-Fong Tseng, Surface roughness classification for castings, Pattern Recognit., vol. 32, no. 3, pp. 389-405, 1999. DOI: 10.1016/S0031-3203(98)00077-6.

[8] Farzaneh Kaji and Ahmad Barari, Evaluation of the surface roughness of additive manufacturing parts based on the modelling of cusp geometry, IFAC-PapersOnLine, vol. 48, no. 3, pp. 658-663, 2015. DOI: 10.1016/j.ifacol.2015.06.157.

[9] M. Hamoud. Surface Roughness Justification in Additive Manufacturing. In The International Conference on Applied Mechanics and Mechanical Engineering, vol. 18, no. 18, pp. 1-11, Military Technical College, 2018.

[10] Bo Whip, Luke Sheridan, and Joy Gockel, The effect of primary processing parameters on surface roughness in laser powder bed additive manufacturing, Int. J. Adv. Manuf. Technol., vol. 103, no. 9-12, pp. 4411-4422, 2019. DOI: 10.1007/s00170-019-03716-z.

[11] Joy Gockel, Luke Sheridan, Brittanie Koerper, and Bo Whip, The influence of additive manufacturing processing parameters on surface roughness and fatigue life, Int. J. Fatigue, vol. 124, pp. 380-388, 2019. DOI: 10.1016/j.ijfatigue.2019.03.025.

[12] Giovanni Strano, Liang Hao, RichardM. Everson, and KennethE. Evans, Surface roughness analysis, modelling and prediction in selective laser melting, J. Mater. Process. Technol., vol. 213, no. 4, pp. 589-597, 2013. DOI: 10.1016/j.jmatprotec.2012.11.011.

[13] K.H. Petter, Surface characterization in Additive Manufacturing An empirical study of angular dependency, Master thesis, Lund university, http://lup.lub.lu.se/student-papers/record/8963731, 2018.

[14] A. Triantaphyllou, C.L. Giusca, G.D. Macaulay, F. Roerig, M. Hoebel, R.K. Leach, B. Tomita and K.A. Milne, Surface texture measurement for additive manufacturing, Surf. Topogr: Metrol. Prop., vol. 3, no. 2, pp. 024002, 2015. DOI: 10.1088/2051-672X/ 3/2/024002.

[15] Mariusz Krol and Tanski Tomasz, Surface quality research for selective laser melting of Ti-6Al-4V alloy, Arch. Metall. Mater., vol. 61, no. 3, pp. 1291-1296, 2016.

[16] Pierre Lhuissier, Charlotte de Formanoir, Guilhem Martin, Rémy Dendievel, and Stéphane Godet, Geometrical control of lattice structures produced by EBM through chemical etching: Investigations at the scale of individual struts, Mater. Des., vol. 110, pp. 485-493, 2016. DOI: 10.1016/j.matdes.2016.08.029.

[17] M. Leary, 4 - Surface roughness optimisation for selective laser melting (SLM): Accommodating relevant and irrelevant surfaces. In: Milan Brandt, editor, Laser Additive Manufacturing, Woodhead Publishing Series in Electronic and Optical Materials. Woodhead Publishing, Elsevier LTD, 2017.

[18] Bastien Vayssette, Nicolas Saintier, Charles Brugger, and Mohamed El May, Surface roughness effect of SLM and EBM Ti-6Al-4V on multiaxial high cycle fatigue, Theor. Appl. Fract. Mech., vol. 108, pp. 102581, 2020. DOI: 10.1016/j.tafmec.2020.102581.

[19] Bastien Vayssette, Nicolas Saintier, Charles Brugger, Mohamed El May, and Etienne Pessard, Numerical modelling of surface roughness effect on the fatigue behavior of Ti-6Al-4V obtained by additive manufacturing, Int. J. Fatigue, vol. 123, pp. 180-195, 2019. DOI: 10.1016/j.ijfatigue.2019.02.014.

[20] A. Ghumatkar, S. Budhe, R. Sekhar, M.D. Banea, and S.D. Barros, Influence of Adherend Surface Roughness on the Adhesive Bond Strength, Latin Am. J. Solids Struct., vol. 13, no. 13, pp. 2356-2370, 2016. DOI: 10.1590/1679-78253066.

[21] Kock-Yee Law, Definitions for hydrophilicity, hydrophobicity, and superhydrophobicity: getting the basics right, J. Phys. Chem. Lett., vol. 5, no. 4, pp. 686-688, 2014. DOI: 10.1021/ jz402762h.
[22] Sina Ebnesajjad, 3 - surface tension and its measurement. In Sina Ebnesajjad, editor, Handbook of Adhesives and Surface Preparation, Plastics Design Library, William Andrew Publishing, Oxford, 2011.

[23] H.Y. Erbil, Surface chemistry of solid and liquid interfaces By HY Erbil, ChemPhysChem, vol. 9, no. 4, pp. 646-647, 2006.

[24] Abraham Marmur, A guide to the equilibrium contact angles maze, Contact Angle Wettability Adhes., vol. 6, no. 1, pp. 3-18, 2009.

[25] D.K. Owens and R.C. Wendt, Estimation of the surface free energy of polymers, J. Appl. Polym. Sci., vol. 13, no. 8, pp. 1741-1747, 1969. DOI: 10.1002/app.1969.070130815.

[26] Cheng Piao, Jerrold Winandy, and Todd Shupe, From hydrophilicity to hydrophobicity: a critical review: Part I. Wettability and surface behavior, Wood Fiber Sci., vol. 42, no. 4, pp. 490-510, 2010.

[27] Malcolm E. Schrader, Young-Dupre Revisited, Langmuir, vol. 11, no. 9, pp. 3585-3589, 1995. Publisher: American Chemical Society. DOI: 10.1021/la00009a049.

[28] B. Wysocki, J. Idaszek, J. Zdunek, K. Rożniatowski, M. Pisarek, A. Yamamoto, W. Świeszkowski, The influence of selective laser melting (SLM) process parameters on in-vitro cell response, Int. J. Mol. Sci., vol. 19, no. 6, pp. 1619, 2018. DOI: 10.3390/ijms19061619.

[29] Ophélie Raimbault, et al., The effects of femtosecond laser-textured Ti-6Al-4V on wettability and cell response, Mater. Sci. Eng. C Mater. Biol. Appl., vol. 69, pp. 311-320, 2016. DOI: 10. 1016/j.msec.2016.06.072.

[30] R. Zahran, J.I. Rosales Leal, M.A. Rodriguez Valverde, and M.A. Cabrerizo Vilchez, Effect of hydrofluoric acid etching time on titanium topography, chemistry, wettability, and cell adhesion, PLoS One, vol. 11, no. 11, pp. 1-12, 2016. DOI: 10 . 1371/journal.pone.0165296.

[31] K.J. Kubiak, M.C.T. Wilson, T.G. Mathia, and Ph Carval, Wettability versus roughness of engineering surfaces, Wear, vol. 271, no. 3-4, pp. 523-528, 2011. DOI: 10.1016/j.wear.2010.03.029.

[32] Gabriela Strnad, Nicolae Chirila, Cecilia Petrovan, and Octav Russu, Contact angle measurement on medical implant titanium based biomaterials, Proc. Technol., vol. 22, pp. 946-953, 2016. DOI: 10.1016/j.protcy.2016.01.094.

[33] I. Yanagisawa, H. Sakuma, M. Shimura, Y. Wakamatsu, S. Yanagisawa, and E. Sairenji, Effects of" wettability" of biomaterials on culture cells, J. Oral Implantol., vol. 15, no. 3, pp. 168-177, 1989.

[34] E.A. Vogler, Thermodynamics of short-term cell adhesion in vitro, Biophys. J., vol. 53, no. 5, pp. 759-769, 1988. DOI: 10. 1016/S0006-3495(88)83156-4.

[35] Yingying Li, et al., Surface wettability switched cell adhesion and detachment on conducting polymer nanoarray, Adv. Mater. Interfaces, vol. 3, no. 19, pp. 1-4, 2016.

[36] Ann Wennerberg and Tomas Albrektsson, Effects of titanium surface topography on bone integration: a systematic review, Clin. Oral Implants Res., vol. 20, pp. 172-184, 2009. DOI: 10. 1111/j.1600-0501.2009.01775.x.

[37] Nicolas Soro, Nicolas Saintier, Hooyar Attar, and MatthewS. Dargusch, Surface and morphological modification of selectively laser melted titanium lattices using a chemical post treatment, Surf. Coat. Technol., vol. 393, pp. 125794, 2020. DOI: 10.1016/j. surfcoat.2020.125794.

[38] E.S. Gadelmawla, M.M. Koura, T.M.A. Maksoud, I.M. Elewa, and H.H. Soliman, Roughness parameters, J. Mater. Process. Technol., vol. 123, no. 1, pp. 133-145, 2002. DOI: 10.1016/ S0924-0136(02)00060-2.

[39] Pierre-Gilles de Gennes, Françoise Brochard-Wyart, and David Quéré, Wetting and long-range forces. In: Pierre-Gilles de Gennes, Françoise Brochard-Wyart, and David Quéré, editors, Capillarity and Wetting Phenomena: Drops, Bubbles, Pearls, Waves, Springer-Verlag, New York, 2004.

[40] E. Bormashenko, Wetting of Real Surfaces, vol. 19, Walter de Gruyter GmbH \& Co KG, Berlin/Boston, 2018. 
[41] Z. Li, C. Liu, B. Wang, C. Wang, Z. Wang, F. Yang, J. Wang. Heat treatment effect on the mechanical properties, roughness and bone ingrowth capacity of 3D printing porous titanium alloy. RSC advances, vol. 8, no. 22, pp. 12471-12483, 2018.

[42] B. Wysocki, J. Idaszek, K. Szlązak, K. Strzelczyk, T. Brynk, K.J. Kurzydłowski, W. Świesszkowski, Post processing and biological evaluation of the titanium scaffolds for bone tissue engineering, Materials, vol. 9, no. 3, pp. 1-19 2016. DOI: 10.3390/ ma9030197.

[43] E.M.M. Sutter and G.J. Goetz-Grandmont, The behaviour of titanium in nitric-hydrofluoric acid solutions, Corros. Sci., vol. 30, no. 4-5, pp. 461-476, 1990.

[44] Robert N. Wenzel, Surface roughness and contact angle, J. Phys. Chem., vol. 53, no. 9, pp. 1466-1467, 1949. September DOI: $10.1021 / \mathrm{j} 150474 \mathrm{a} 015$.

[45] G. Schnell, S. Staehlke, U. Duenow, B. Nebe, and H. Seitz, Femtosecond laser nano/micro textured ti6al4v surfaces-effect on wetting and mg-63 cell adhesion, Materials., vol. 12, no. 13, pp. 2210-2223, 2019. DOI: 10.3390/ma12132210.

[46] Narendra Dahotre, Sameer Paital, Anoop Samant, and Claus Daniel, Wetting behaviour of laser synthetic surface microtextures on Ti-6Al-4V for bioapplication, Philos Trans A Math Phys Eng Sci., vol. 368, no. 1917, pp. 1863-1889, 2010. 04 DOI: 10.1098/rsta.2010.0003.

[47] Sicknan Soares da Rocha, Gelson Luis Adabo, Guilherme Elias Pessanha Henriques, and Mauro Antonio de Arruda Nobilo, Vickers hardness of cast commercially pure titanium and Ti-6Al-4V alloy submitted to heat treatments, Braz. Dent. J., vol. 17, no. 2, pp. 126-129, 2006.

[48] A.B.D. Cassie, and S. Baxter, Wettability of porous surfaces, Trans. Faraday Soc., vol. 40, pp. 546, 1944. DOI: 10.1039/ tf9444000546.

[49] Gyoko Nagayama and Dejian Zhang, Intermediate wetting state at nano/microstructured surfaces, Soft Matter., vol. 16, no. 14, pp. 3514-3521, 2020. DOI: 10.1039/C9SM02513H. 